NBER WORKING PAPER SERIES

\author{
AN ECONOMIC ANALYSIS OF CHILDREN'S HEAITH \\ AND INTELLECTUAL DEVELOPMENT \\ Linda Nasif Edwards \\ Queens College and Graduate School of the City \\ University of New York and NBER \\ Michael Grossman \\ Graduate School of the City University of \\ New York and NBER \\ Workıng Paper No. 180
}

CENTER FOR ECONOMIC ANALYSIS OF HLMAN BEHAVIOR $\Lambda$ ND SOCIAL INSTITUTIONS

National Bureau of Economic Research. Inc.

261 Madıson Avenue, New York, N.Y. 10016

May 1977

Preliminary; Not for Quotation

NBER working papers are distributed informally and in 1 imited number for comments only. They should not be quoted without written permission.

Thls report has not undergone the review accorded offlclal NBER nublicattons; in particular, it has not yet been submitted for approval by the Board of Directors.

Research for this paper was supported by PHS Grant Number 5 pOI HSO045I from the National Center for Health Services Research, HRA, to the National Bureau of Economic Research and by a grant from the
Robert Wood Johnson Foundation to the NBER. 


\section{AN ECONOMIC ANALYSIS OF CHILDREN'S HEALTH AND INTELLECTUAL DEVELOPMENT}

Linda Nasif Edwards and Michael Grossman*

The role of health and intellectual development in the determination of economic and social well-being is a subject of increasing concern for both social science and public policy. Numerous studies have demonstrated that adults' earnings and life expectancy depend on their schooling, health, and ability. ' ${ }^{1}$ others suggest important causal relationships running from health and intelligence at early stages in the life cycle to years of formal schooling completed and from schooling to adults' health. A common theme in these studies as well as in the massive literature on the effects of home environmental variables on children's cognitive development is that well-being at later stages in the life cycle depends on well-being at early stages.

The basic purpose of our research is to contribute to an understanding of the joint determination of children's cognitive development and their health. Although there is a large literature concerning the first

เ

This is a revised version of a paper presented at a conference on "The Family and the Subsequent Development of the Child" sponsored by the Mathematical Social Science Board in Stanford, California, March 24-26, 1977. A preliminary version of the paper also was presented at a Health Economics Research Organization (HERO) session at the Allied Social Science Associations 1976 meetings in Atlantic City, New Jersey, September 16-18. We would like to thank Harold J. Dupuy, Reuben Gronau, Edward Lazear, Arleen Leibowitz, Irving F. Leveson, Robert Lipsey, Robert $\mathrm{T}$. Michael, Barry $\mathbb{M}$. Popkin, Stephen A. Richardson, Sherwin Rosen, Nigel Tomes, and Robert J. Willis for helpful comments and suggestions; and Ann Dukes Colle and Jacob
Gesthalter for research assistance.

1

For a partial survey of the literature on relationships among earnings, schooling, health, and intelligence of adults and children, see Grossman
(1975). 
of these issues, there has been little work on the latter. ${ }^{2}$ we also explore interrelationships between various aspects of children's physical health and their intellectual development and, in particular, attempt to answer tine important question of whether poor health retards the cognitive development of children. ${ }^{3}$

More specifically, this paper, which is part of a larger project, examines the deteminants of cognitive development and health of children from six to eleven years of age in Cycle II of the U.S. Health Examination Survey. We focus on the roles of home environmental variables and proxies for the endowed (initial or inherited) level of health in the current nealth and development functions with a view toward uncovering similarities in or differences between health and development effects. The empirical work is guided by an insight provided by a theoretical model of intergenerational transfers of human and non-human wealth: namely, to understand the behavior of parents with respect to their children's health and development, it is important to distinguish

2

Starfield (1975) emphasizes that, although many persons have studied the effects of medical care and socioeconomic characteristics on infant mortality, relatively few have examined the effects of these variables on the nealth of children who survive the first year of life. For a few Hu (1973); Kessner (1974); Haggerte, Kaplan, Lave, and Leinhardt (1972); Inman (1976).

3

Birch and Gussow (1970), whose entire book focuses on the effects of health on learning, point out that most of the evidence they bring to tigation of the is indirect because "... there has been little invespoor children specific relationships between the physical status of investigate these relationships development ( $D .10) . "$ For one attenpt to Broman, Nichols, and Kennedy (1975) sample of very young children, see 
low income families from high income families. Clearly, this is a policy relevant insight, for public policy often is aimed at low income groups. Our results indicate that it would be incorrect to formulate policies directed at improving the welfare of children in low income families on the basis of empirical results derived from examining the population at large. 


\section{The Model}

In this section we outline an economic model of children's health and intellectual development. The model serves as a vehicle for organizing and interpreting empirical research with a data set as complex as the Health Examination Survey. While our model draws heavily on analyses of intergenerational transfers by Becker (1967, 1974); Friedman and Leibowitz (1975); Ishikawa (1975); Becker and Tomes (1976); and Tomes (1977), one of its novel aspects is that it suggests appropriate ways to estimate the effects of parents' income and other variables on children's health and development.

\section{A. General Analytical Franework}

To start the analysis, assume that parents make decisions over two periocs $(0,1)$ or stages in their life cycle. In period 0 their children are completely dependent upon them for financial support, while in period I the children become financially independent. I The parents' utility function can be specified as

$$
\mathrm{U}=\mathrm{U}\left(\mathrm{C}_{0}, \mathrm{C}_{1}, \mathrm{~N}, Q\right)
$$

where $C_{0}$ and $C_{1}$ represent their consumption in each period, $N$ is their total number of children, and $Q$ is quality per child. This utility

${ }^{1}$ For a model of intergenerational transfers in which the period of dependency is treated as an endogenous variable and associated with years of formal schooling completed by children, see Ishikawa (1975). 
function embodies the assumption that within a given family tie quality of each child is the same. ${ }^{2}$

In a general model, child quality would depend on the child's expected lifetime wealth, health, intellectual development, and perhaps other factors, so that these variables would enter the utility function as separate arguments. To simplify the analysis and to obtain testable propositions, we assume, however, that child quality is determined solely by the child's lifetime wealth or, equivalently, by the present value of earned and nonearned income in the period of independence:

$$
Q=B+W(H, D) \text {. }
$$

In this equation $B$ is a financial transfer or becuest made by parents to the child at the beginning of the period of independence ${ }^{3}$ and $W$ is the present value of earnings. Earnings are assumed to depend on the stocks of physical health capital (H) and knowledqe or cognitive development capital (D) ; wich are two eomponents of human capital, In farticular, the marginal

2

For a model in which the quality of each child in the family can differ, see Becker and Tomes (1976). They show that quality would tend to be equalequilibrium conditions in their model.

3 the period of independence rather that financial transfers are made during does not affect the analysis if the tax treat beginning. This, however, changed and if individuals face "good" treatment of the transfers are unBlincer (1973). 
products of these stocks $\left(W_{H}=Q_{H}\right.$ and $\left.W_{D}=Q_{D}\right)$ are positive. 4

The amount of health and development are given by the following identities (in the absence of depreciation):

$$
\begin{aligned}
& H=H_{0}+I \\
& D=D_{0}+G,
\end{aligned}
$$

where $\mathrm{H}_{0}$ is the initial or inherited stock of health (genetic endowment of health), I is net investment in health, $D_{0}$ is the initial or inherited stock of development, and $G$ is net investment in development. 5 To complete the rudiments of the model, we specify production functions of investments in health and development as

$$
\begin{aligned}
& I=I\left(M, F, H_{0}, D_{0}\right) \\
& G=G\left(X, F^{\prime}, H_{O^{\prime}}, D_{0}\right) .
\end{aligned}
$$

\section{4} Throughout this paper, a single capital letter subscript denotes a
first-order partial derivative, while a double order partial derivative. Thus,

$$
w_{H} \equiv \partial \mathrm{W} / \partial H, w_{H H} \equiv \partial^{2} W / \partial H^{2}, w_{D H} \equiv \partial^{2} W / \partial D \partial H
$$

etcetera. In Edwards and Grossman (1976), we discuss plausible signs of about these signs in this paper. equation (2) is constant paper. Note that the marginal product of $B$ in $\left.Q_{B D}=0\right)$.

$5_{\text {We treat }} H_{0}$ and $D_{0}$ as exogenous variables. In a full model they would have endogenous components that would be determined by factors such as
prenatal medical care and parental characteristics. 
In equations (5) and (6), $M$ is a vector of endogenous inputs in the health production function, $\mathrm{x}$ is a vector of endogenous inputs in the development production function, and $F$ and $F^{\prime}$ are vectors of exogenous variables that affect the efficiency of the production process. Examples of elements in the $M$ vector include medical care, nutrition, housing quality, and parents' time; while examples of elements in the $x$ vector include school quality, home learning aids, and parents' time. Examples of elements in $F$ and $F^{\prime}$ are parents' schooling and parents' age. 6 we assume that equations (5) and (6) do not vary among children in a given family and further that all children in a given family have identical endowments $\left(H_{0}\right.$ and $\left.D_{0}\right)$. These assumptions insure that the optimal amounts of $B, H$, and $D$ as well as $Q$ will be the same for all children in the family. 7

Note that the initial stocks of health and development $\left(\mathrm{H}_{0}, \mathrm{D}_{0}\right)$ are included in the production functions of both $I$ and $G$. While no assumption is made at this time with respect to the directional effects of these initial stocks on $I$ and $G$, this flexible specification allows for a number of possibilities. For example, the effect of medical care inputs on changes in health may be greater when an individual's stock of health is at a lower level (i.e. $\left.\partial I / \partial H_{0}<0\right)$. Or, children with greater inherited intellectual ability may augment that ability more easily (i.e.

6 The vectors $F$ and $F$ ' might or might not be identical.

7

7 If the production functions and/or initial endowments of children vary, $B, D$, and $H$ would tend to differ among children but $Q$ would not (see Becker and Tomes 1976). In future work we may pursue theoretical and empirical analyses in which endownents vary among children in the same 
$\left.\partial G / \partial D_{D}>0\right) .^{8}$ Further, this specification allows for an interplay between health and development, and in particular, it allows for the possibility that lok initial health levels will affect realized intellectual ability. 9 Parents maximize the utility function given by equation (1) subject to the children's quality function [equation (2)], the initial stocks of healtin and development, the production functions of health and development [equations (5) and (6)], and their wealth constraint. The last constraint has the form

$$
S=c_{0}+c_{1}(1+r)^{-1}+N\left[B(1+r)^{-1}+p M+q X\right],
$$

where $I$ is the rate of interest, $p$ is the price of $M, q$ is the price of $x$, and the quantity $B(1+r)^{-1}+p M+q X$ is the present value of expenditures per child. 10

8 This assumption is made by Becker and Tomes (1976). On the other hand, Eloom's (1964) findings suggest that the initial level of measures such as height, IO, and school achievement does not affect the rate at which a child
augments these measures.

9

9 Most of the literature on the interaction between child health and development emphasizes the impact of low levels of investments in health at the preschool stage of the child's life cycle on subsequent cognitive development (for example, Birch and Gussow 1970; Broman, Nichols, and Kennedy 1975). To examine the impact of both current and initial health on development or to allow for full simultaneity between health and development, it would be necessary to introduce more than one period of
dependency.

${ }^{10}$ From now on we treat $M$ and $X$ as scalars rather than vectors. 
From the first-order conditions for the maximization of utility with respect to $C_{0}, C_{1}, N, B, M$, and $x_{1}^{11}$ we obtain

$$
\left(p / Q_{M}\right)=\left(q / Q_{X}\right)=(1+r)^{-1}
$$

This is the faniliar result (which can be obtained directly by minimizing the cost of producing a given amount of Q) that the ratio of a price of an input to its marginal product in the $Q$ function must be equal for all inputs. In the case of $B$, the price of $B$ relative to the price of parents' current consumption $\left(C_{0}\right)$ is $(1+r)^{-1}$ because in order to raise $B$, and hence $Q$, by one dollar, $C_{0}$ must fall by $(1+r)^{-1}$ dollars. The marginal product of $B$ is constant at one dollar. The cormon value of the two equalities in (8) may be interpreted as the marginal cost of quality, which is completely determined by the interest rate once the optimal

${ }^{11}$ The first-order conditions are

$$
\begin{aligned}
& U_{0}=\lambda \\
& U_{1}=\lambda(1+r)^{-1} \\
& U_{N}=\lambda z \\
& U_{Q}=\lambda N(1+r)^{-1} \\
& U_{Q^{Q}}=\lambda N p \\
& U_{Q^{Q} X}=\lambda \mathrm{Nq},
\end{aligned}
$$

where $U_{i}$ is the marginal utility of $C_{i^{\prime}} \lambda$ is the marginal utility of wealth, and $z$ defines the present value of expenditures per child $\left[\mathrm{B}(1+r)^{-1}+\right.$
$\mathrm{pM}+\mathrm{qX}]$. 
inputs are chosen. ${ }^{12}$ secona-order conditions require that the marginal products of $M$ and $X$ fali as $M$ and $X$ increase, respectively, and that children's earnings $(W)$ is produced subject to rising marginal cost. ${ }^{13}$

To summarize this model, children's wealth at the inception of independence has a future earnings component and a bequest component. Parents' investments aimed at increasing chiloren's earning power are subject to decreasing returns, while those that are in the form of a bequest are not. Cost minimization (or utility maximization) dictates that no matter how much wealth (Q) parents wish to transfer to their children, the amount of earning power or human capital (w) they will provide is the same and is totally determined by the interest rate and the nature of the marginal cost schedule of $W$. Put differently, the least-cost expansion path of $Q$ is one in which $M$ and $X$ and therefore $H, D$, and $W$ remain constant. If the optimal level of $W$ is greater than their desired $Q$, parents simply leave their children a negative bequest in the form of net debts. $12 \mathrm{An}$ alternative interpretation of equation ( 8 ) for the optimal quanti-
ties of $M$ and $x$ is that $\left(Q_{M} / p\right)-1$ and $\left(g_{X} / q\right)-1$ define the marginal rates of return on investments in health and development. In equilibrium these rates of return must equal the rate of return on a financial transfer $(r)$. 13 The relevant second-order conditions are

$$
\begin{aligned}
& \mathrm{Q}_{\mathrm{MM}}<0 \\
& \mathrm{l}_{\mathrm{XX}}<0 \\
& \mathrm{~g}_{\mathrm{MM} \mathrm{XX}}>\mathrm{Q}_{\mathrm{MX}}^{2} .
\end{aligned}
$$

These conditions follow because the utility function is "weakly separable" in $B, M$, and $X$ and because the marginal product of $B$ in the $Q$ function is constant $\left(Q_{\mathrm{BB}}=Q_{\mathrm{BM}}=Q_{\mathrm{BX}}=0\right.$ ). 
These ideas are depicted graphically in Figure 1, which shows the determination of the optimal amounts of $Q, W$, and $B$ for three different families. $^{14}$ The curve labeled MC shows the relationship between $W$ and the marginal cost of $W$ for combinations of $M$ and $X$ that satisfy $\left(p / Q_{M}\right)=\left(q / Q_{X}\right) \cdot{ }^{15}$ The point at which the $M C$ curve intersects the horizontal axis, $W_{0}=W\left(H_{0}, D_{0}\right)$, is that level of lifetime earnings if no investments in health and development are made during the period of dependence. The curves labeled $d_{1}, d_{2}$, and $d_{3}$ depict the relationship between the marginal benefit of $Q\left(d=U_{Q} / \lambda N\right.$, where $\lambda$ is the marginal utility of wealth) and $Q$ at three different wealth levels $\left(s_{3}>s_{2}>s_{1}\right)$. These functions may be interpreted as compensated (utility or real income constant) demand functions for quality. The optimal amount of $\mathrm{W}$ always is given by $Q_{2}$, where MC equals $(1+r)^{-1}$. The optimal amounts of

14 This diagram and our discussion of the determination of the optimal
amounts of $Q, W$, and $B$ are closely related to $F$ isher's (1930) analys is of investment and interest.

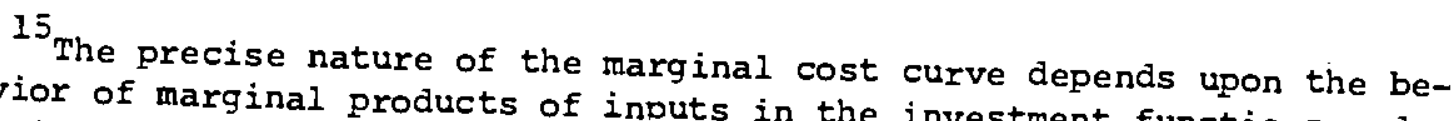
havior of marginal products of inputs in the investment functions and
marginal products of stocks in the earnings we assume diminishing marginal productivity function. In the diagram $G<0$ ) and $G<$ inputs ( $I_{M M}<0$ and $\left.\mathrm{G}_{\mathrm{XX}}<0\right)$ and constant marginal productivity of stocks $\left(\mathrm{W}_{\mathrm{HH}}=\mathrm{W}_{\mathrm{DD}}=0\right)$. An alternative set of assumptions would be constant marginal productivity
of inputs ( $\left.{ }_{M M}=G_{X X}=0\right)$ and diminishing $\left(w_{H}<0\right.$ and $\left.w_{<}<0\right)$. These a $\left(W_{\mathrm{HH}}<0\right.$ and $\left.W_{D D}<0\right)$. These alternative assumptions would not alter the sign of the slope of the MC function and therefore would not alter our basic analysis. It also should be noted that for simplicity of exposicould take a variety of forms is drawn as a straight line. In fact, it a curve concave to the origin, or a straight 


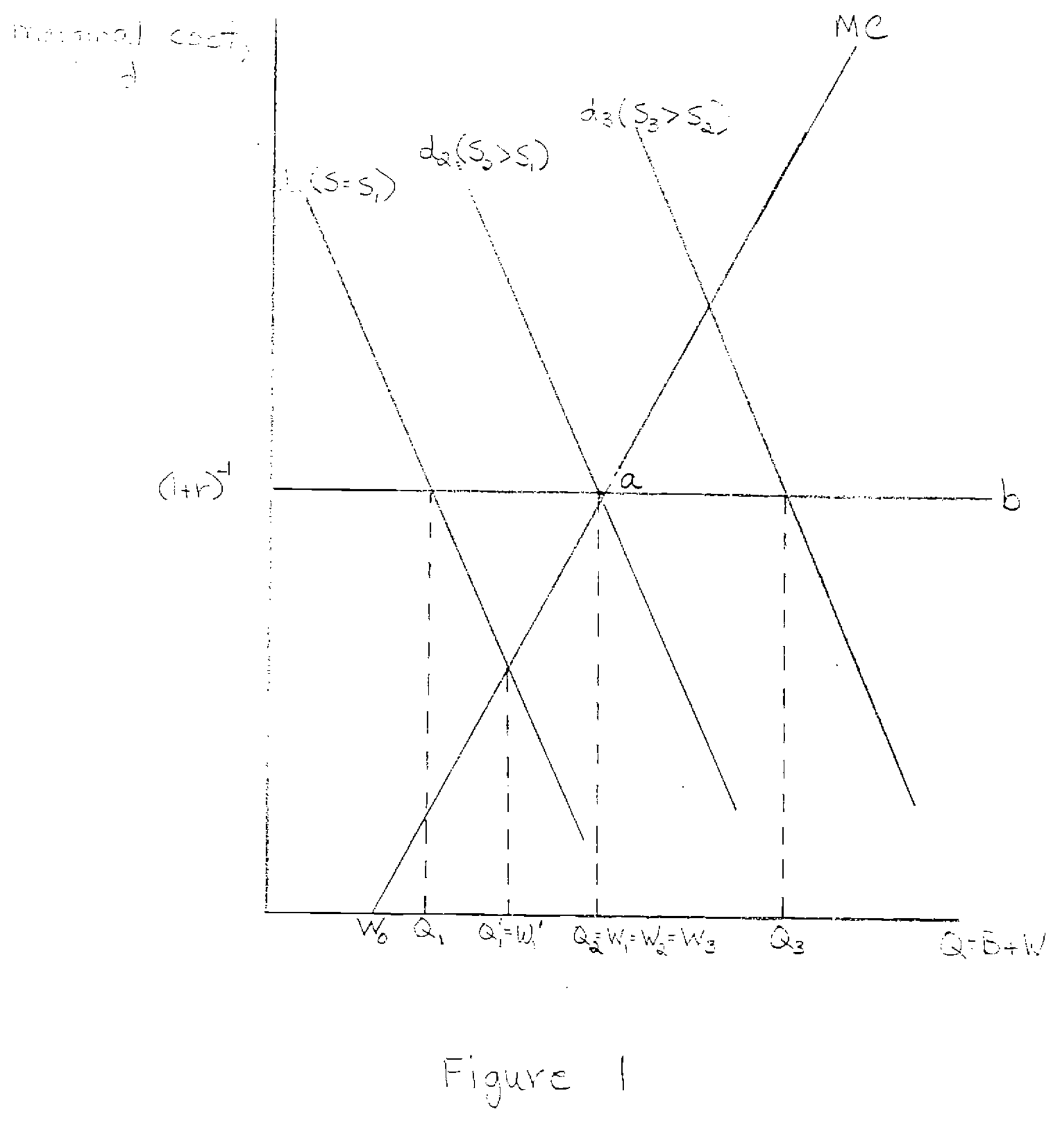


$Q\left(Q_{1}, Q_{2}\right.$, and $\left.Q_{3}\right)$ are determined by the intersections of the downward sloping demand functions and the supply curve of Q--the horizontal line whose height equals $(1+r)^{-1}$.

For family 2 , the intersection of its demand $\left(d_{2}\right)$ and supply curves is at $Q_{2}$. Since $Q_{2}$ is the optimal $w$ for all families, the financial transfer (B) equals zero for family 2. Family 3 makes a positive financial transfer equal to distance $\ell_{2} \ell_{3}$, while family 1 makes a negative financial transfer equal to distance $\Omega_{2} \Omega_{1}$. Thus, in this model, differences in human capital of chilaren are determined solely by differences in endowments and in marginal costs of producing this capital. Differences among families in their demand for children's quality have no bearing on differences in children's realized human capital.

So far we have assumed that the financial transfer can be positive, zero, or negative. In analyses of intergenerational transfers that are similar țo ours, Becker (1967); Friedman and Leibowitz (1975); Ishikawa (1975); Becker and Tomes (1976); and Tomes (1977) point out that it is reasonable to impose a solvency constraint, a constraint that parents cannot leave debts to their children, or that $\mathrm{B} \geq 0$. In terms of Figure 1 , the imposition of a solvency constraint changes the supply curve of $Q$ as follows. The "constrained" supply curve coincides with the MC curve up to the point where $M C=(l+r)^{-1}$ and thereafter is horizontal at $(1+r)^{-1}$ (schedule $w_{0} a b$ ). The imposition of the solvency constraint does not affect the quantities of $Q$ and $W$ selected by families 2 and 3 , but it does alter the quantities selected by family 1. Family 1 chooses quality $Q_{1}^{\prime}$, where its demand function intersects the MC function. since $Q_{1}^{\prime}$ also gives the quantity of $W$ if $B$ equals zero $\left(Q_{1}^{\prime}=W_{I}^{\prime}\right)$, the parents in family 1 
choose a larger quantity of $Q$ in the constrained case (compare $Q_{1}$ and $Q_{1}^{\prime}$ ) but a smaller quantity of $w$ (compare $w_{1}^{\prime}=Q_{1}^{\prime}$ and $w_{1}=Q_{2}$ ).

We impose the solvency constraint in the rest of our analysis. ${ }^{16}$ As a consequence, households whose demand functions intersect the supply function in its upward sloping segment $\left(W_{O}\right.$ a) will demand more $H, D, X$, and $M$ as their income rises. That is, we anticipate a positive effect of parents' income or wealth on child health or development at relatively low wealth levels, where $B$ equals zero, but not at relatively high wealth levels, where $B$ exceeds zero. 17

\section{B. Demand Functions for Health and Development}

The above framework suggests a two-regime specification of demand functions for children's earnings (W), children's health capital (H), children's development capital (D), and endogenous inputs in the production of health and development ( $M$ and $X)$. Since we analyze only health and development empirically in this paper, hereafter we focus on the properties of their demand functions. ${ }^{18}$ Parents who do not make financial transfers to their cilidren ( $B=0$ ) are members of Regime 1 and have demand functions of the form

${ }^{16}$ Formally, if the constraint is binding, then the equilibrium condition for $B$ is replaced by the inequality $\left(U_{Q} / \lambda N\right)<(1+r)^{-1}$.

17 For similar conclusions, see Becker (1967); Friedman and Leibowitz (1975); Ishikawa (1975); Becker and Tomes (1976); and Tomes (1977).

18
For an analysis of input demand functions, see Edwards and Grossman 


$$
\begin{aligned}
& H=\varnothing_{1}\left(S, p, q, F, F^{\prime}, H_{0}, D_{0}\right) \\
& D=\Psi_{1}\left(S, p, q, F, F^{\prime}, H_{0}, D_{0}\right) .
\end{aligned}
$$

Parents who do make positive financial transfers to their children $(B>0)$ are members of Regime 2 and have demand functions of the form

$$
\begin{aligned}
& H=\varnothing_{2}\left(r, p, q, F, F^{\prime}, H_{0}, D_{0}\right) \\
& D=\Psi_{2}\left(r, p, q, F, F^{\prime}, H_{0}, D_{0}\right)
\end{aligned}
$$

These demand functions are reduced form equations in the sense that the marginal cost of $W$ has been replaced by its determinants ( $P, q, F, F^{\prime}, H_{0}$, and $\left.D_{0}\right)$.

We have already pointed out that parents' income or wealth (S) has a positive effect on $H$ or $D$ for members of Regime 1 , but not for members of Regime 2. With respect to the rate of interest $(r)$, it is obvious from Figure 1 that an increase in $r$ raises children's quality (Q), lowers children's earnings $(W)$, and lowers $H$ and $D$ for members of Regime 2, but has no effect on these variables for members of Regime 1 . 
The six remaining variables enter the demand functions for $M$ and $D$ in both regimes: two input prices $(p$ and $q$ ), two efficiency measures ( $F$ and $\left.F^{\prime}\right)$, and two endowment measures $\left(H_{0}\right.$ and $\left.D_{0}\right)$. In general, the direction of the effect of any of these variables is the same in each regime, although the magnitude of the effect differs. For example, in the demand curve for $k$, the own innut price (p) effect is negative, the Own efficiency (F) effect is positive, and the own endowment ( $H_{0}$ ) effect is positive. The signs of the cross input price $(0)$, cross efficiency $\left(F^{\prime}\right)$, and cross endowment $\left(D_{0}\right)$ effects are ambiguous. Similar statements can be made with regard to own and cross effects in each regime's demand curve for $D .19$

As an illustration of how differences can arise in the maonitude of effects of common deteminants of $\mathrm{H}$ or $\mathrm{D}$ in the two regimes, consider the simole model depicted in Figure 2. The demand curve for $Q$ of a family in Regime $I$ is given by $d_{1}$, while the corresponding demand curve of a family in. Regime 2 is given by $d_{2}$. Each family has the same marginal cost curve " 0 ab. An increase in efficiency or a reduction in input prices would cause the upward sloping segment of the marginal cost curve to rotate to the right from $W_{0} a$ to $W_{0} a^{\prime}$. Family 1 would increase its optimal amount of $Q$ or $W$ from $Q_{1}=W_{1}$ to $Q_{1}^{\prime}=W_{1}^{\prime}$. Family 2 would increase its optimal amount of $W$ from $\mathrm{W}_{2}$ to $\mathrm{W}_{2}^{\prime}$, but would not change its optimal amount of $\mathrm{g}$. Although both families would demand more $n$, the expansion would be greater

${ }^{19}$ For a detailed analysis of own and cross effects, see Edwards and Grossman (1976). 
I -14

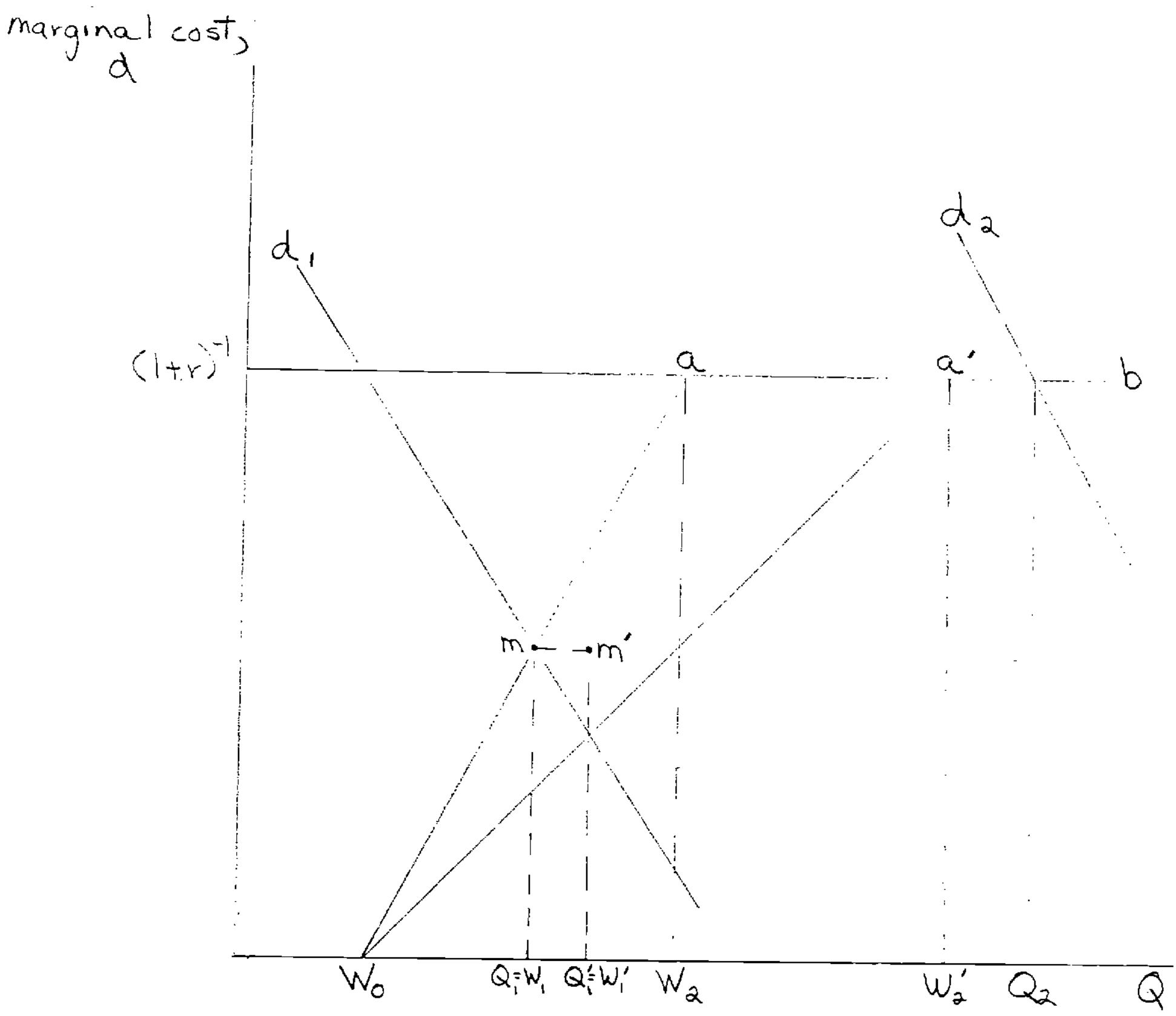

Figure 2 
5. Visual and hearing acuity, as defined above.

Efficiency in the production of both types of children's human capital is measured by the parents' educational attainment (MEDUCAT and FEDUCAT). ${ }^{16}$ since mothers traditionally spend more time with children than do fathers, MEDUCAT should have a greater effect in the reduced form equations than FEDUCAT (as measures solely of inherited Io, they would be expected to have equal effects).

Information about the prices of the inputs in the health and development production functions is difficult to obtain for the cycle il data set. There are no direct measures of relevant prices such as the price of medical care or the price of parents' time (or their wage rates). Moreover, since the precise locality of each observation cannot be identified, it is not possible to estimate these prices with local market data. Therefore, we use a set of crude proxy variables to control partiallv for these prices.

To control for price variation due to region and size of place of residence, we enter a set of three region dummy variables (denoted NEAST, MWEST, SOUTH) and four sizes of place variables (denoted URB1, URB2, URB3, NURE). Information about whether or not the child's vision has been corrected (SEEG, NSEEG) provides some indication of the price of medical care. To hold constant the cost of the mother's time (probably one of the most important inputs in both the health and development functions), we control for the primary activity of the mother (full-time work, part-time work, or no

16 The literature on household production functions commonly treats parental education as an efficiency variable. 
To conclude, our model has an important implication for the estimation of demand curves for children's health and intellectual development. Besides suggesting the relevant explanatory variables, it calls attention to the need for allowing for interactions between parents' income, clearly an important determinant of the relevant regime, and determinants of the marginal cost schedule of children's earnings. 
II. Data and Estimation

Actual estimation of tine relationsinips represented by equations (9) tinrough (12) is conditioned by the nature of the data. In this section we describe our data set, specify which empirical measures will be used to represent the theoretical variables in (9) through (12), and outline the statistical techniques to be used for estimation.

A. The Data

Our data set is Cycle II of the U.S. Health Examination Survey (HES) conducted by the National Center for Health Statistics (NCHS). Cycle II is a nationally representative sample of 7,119 children aged six to eleven years examined over the 1963-65 period. ${ }^{1}$ This sample is an exceptionally rich source of information about chilaren's health, their intellectual development, and the characteristics of their families. More specifically, the data comprise complete medical and developmental histories of each child provided by the parent, information on family socioeconomic characteristics, birth certificate information, and a school report with data on school performance and classroom behavior provided by teachers or other school officials. Most important, there are objective measures of health from detailed physical examinations and scores on psychological (including vocabulary and achievement) tests. The physical examinations and the psychological tests were administered by the Public Health Service.

Although the sample contains children of all races, for three reasons we restrict our analysis to white children only. First, this procedure

\footnotetext{
${ }^{1}$ For a full description of the sample, the sampling technique, and the data collection, see NCHS (1967a).
} 
avoids the problem associated with alleged "cultural biases" in IQ and achievement tests. Second, in preliminary estimates of equations (9) through (12), it was found that the hypothesis of equality between sets of coefficients for whites and blacks was rejected. Therefore, these groups could not be pooled for purposes of estimation. Third, the black sample alone is too small to allow for reliable coefficient estimates. 2 Our sample is limited further by excluding children who do not live with both of their natural or adopted parents or for whom there were missing data. $^{3}$ The resulting subsample reported on here contains 3,608 children. A caveat concerning the use of the model developed in section I for the analysis of children's health and intellectual development in Cycle II of the HES is the following: the model and its predictions apply to children's health and development at the age of independence rather than to children in mid-childhood. This discrepancy does not undermine the usefulness of our model as long as there are no systematic differences across families in the time paths of human capital formation. Given such an assumption, our basic predictions will hold equally well for the six to eleven year-old cohort as for young adults at the onset of independence.

B. Variable Measures

The measurement (and even the definition) of the theoretical variables that we wish to study--children's health and intellectual development--is a formidable task. Indeed, the measurement of these variables has been the

\footnotetext{
2 The full Cycle II sample contains 6,100 whites, 987 blacks, and 32 "others."

3 proc procedure eliminates children who live with foster parents, stepparents, guarcians, or single, widowed, or divorced parents. It is designed to control for the effects of marital instability. We also exclude the 72 children who turned twelve by the time they had been examined.
} 
subject of a large literature. Oux actual choices of measures will be determined primarily by the data available in Cycle II and will be guided by the existing literature.

\section{Measures of Health}

The issue of how to measure children's health is very much an unresolved one, even among professionals in the area of public health. 4 Most recent. studies of cilidren's health have used data taken from one or more of the following categories: measures of disability, measures related to the incidence of abnomal conditions, and measures derived from parental assessments of childxen's health (for example, Wallace 1962; Mechanic 1964; Mindlin and Lobach 1971; Talbot, Kagan, and Eisenberg 1971; Kaplan, Lave, and Leinhardt 1972; Hu 1973; Schack and Starfield 1973; Kessner 1974; Haggerty, Roghmann and Pless 1975; Imman 1976). Although we plan to follow the precedent of these earlier studies, some of the above measures (disability and the incidence of certain physical conditions) are not entirely appropriate to our model because our health variable refers to the child's "permanent" state of health rather than short-run deviations from that "permanent" state. 5 Much childhood disability results from the natural sequence of childhood diseases and acute conditions which do not reflect on the child's "permanent" state of health. 6

4 This is true not only for children's health, but also for adult's health. Sullivan (1966), Berg (1973), and Ware (1976) discuss the general issue of measuring health, and starfield (1975) and schack and starfield (1973) focus on the specific problem of measuring children's health.

5 By "permanent" state of health we mean the child's prospect for life preservation and normal functioning.

6 of course, there is a positive correlation between the two in the sense that a child with poor "permanent" health is more likely to contract acute conditions and to have them for a more extended time period. For example, Birch and Gussow (1970) discuss how nutrition (clearly a determinant of permanent health status) and disease are intimately related. 
The ideal measure of "permanent" health from an empirical perspective is a single measure that appropriately sumarizes all available and relevant information. Health, however, is clearly a multidimensional concept. A single index is not feasible and would not be desirable from a medical point of view. In particular, even if it were clear what the components of such an index should be, there would be no agreement about the weights assigned to each component. In the case of children's health, the derivation of such weights would be especially complicated because some of the components would be development-related: a given observation might indicate low health capital at one stage of development but not at another stage of development. Finally, although a single health status index would be conceptually neat, it is possible that the various components of health will be differentially affected by the socioeconomic factors. Analysis of a set of components rather than a single index will allow us to detect such differential effects.

The set of measures we use are height, the peridontal index, the number of decayed teeth, and the parents' assessment of the child's health. ${ }^{7}$ These are described below.

${ }^{7}$ We selected health measures from the HES based on the advice of John McNamara, M.D., Assistant Professor of Public Health and Pediatrics at Columbia University School of Public Health and Associate Commissioner in the New York City Department of Health; Roy Brown, M.D., Associate Professor of Community Medicine and Pediatrics at the Mount Sinai School of Medicine of the City University of New York; and Thomas Travers, D.D.S., Director of Ambulatory Care in the New York City Department of Health. 
1. IHEIGHT, children's height standardized by the mean and standard deviation of neight for each age-sex group. 8 Height is a standard indicator of children's nutritional status, and good nutrition is an obvious and natural vehicle for maintaining children's health (for example NCHS 1975b).

2. IPERI, the child's peridontal index, which is a good overall index of oral health as well as a positive correlate of nutrition (Russell 1956). Due to the significant age trend in this variable (NCHS 1972b), it is standardized by age in the same manner as IHEIGHT. Higher values of IPERI indicate poorer oral health.

3. IDECAY, the number of decayed primary and permanent teeth, adjusted for age and sex as is IHEIGHT. IDECAY is a supplemental measure of oral health and also reflects nutritional status. Higher values of IDECAY indicate poorer oral health.

4. PFHEALTh, a dichotomous variable that indicates the parents' assessment of the child's current state of health. PFHEALTh equals one when parents assess the child's health as poor or fair and equals zero if they assess it as good or very good.

2. Measures of Intellectual Development

Three measures of intellectual development are used to represent intellectual development capital (D): an IQ measure derived from two subtests from

${ }^{8}$ It is well-known (for example, Bloom 1964) that physical growth rates differ by age and sex. For any observation IHEIGHT is the difference between the child's actual height and the mean height for his or her agesex group divided by the standard deviation of height for that age-sex group. If the actual height of each age-sex group is normally distributed, this standardized measure could be directly translated into the child's height percentile. 
the Wechsler Intelligence Scale for Children (denoted WISC), ${ }^{9}$ and reading and arithmetic test scores on the Wide Range Achievement (denoted RWRAT and AWRAT, respectively). 10 Many persons have criticized these measures of intellectual development, but even more have used them to conduct empirical analyses (for example, the studies cited in Averch et al. 1972). We distinguish between reading and arithmetic achievement because of evidence that among various school achievement measures mathematical achievement is the most important determinant of earnings (Ashenfelter and Mooney 1968; Kenny 1977). Achievement rather than IQ would seem to be most appropriate for our purposes since we wish to measure intellectual development rather than innate ability. It is, however, intellectual development at the onset of independence that is desired, and since IQ has been found to be a good predictor of success at school (for example, Carroll 1973), we use WISC and current achievement (RWRAT and AWRAT) as alternative measures of $D$. All three measures are scaled to

$9^{9}$ The Wechsler Intelligence Scale for Children is a common IQ test, similar to (and highly correlated with results from) the stanfordBinet IQ test. The full test consists of twelve subtests, but only two of these (vocabulary and block design) were administered in the HES. The possible difficulties in the estimation of full scale IQ from these two subtests is examined in NCHS (1972b). For a full discussion of all psychological tests administered in the HES, see NCHS (1966).

10 The Wide Range Achievement Test is a single test that can be given to children of varying ages. In particular, the same test was given to all of the 7,119 children in the sample. (Only twelve-year olds, who are excluded from our basic sample, were given a different version of WRAT.) The two tests used here were found to "... have reasonably good construct validity as judged by their relationship to conventional achievement tests (NCHS 1967b)." 
have means of 100 and standard deviations of 15 for each age-group (fourmonth cohorts are used for WISC and six-month cohorts are used for RWRAT and AWRAT).

\section{Explanatory Variables}

The explanatory variables in the reduced form equations are health and development endowments, prices of the composite health and development inputs, measures of efficiency in the production of health and development capital, family income, and the rate of return on financial investments. The rate of return on financial investments is assumed to be constant for all members of our sample. Measures of the other theoretical variables are described below and are defined precisely in Table 1. The table also contains definitions of the seven dependent variables described above.

The health endowment of the child is represented by the following measures: ${ }^{11}$

1. Birth weight, measured by the dichotomous variable IIGHT. A child is considered to have low birth weight if he or she weighs less than 2,500 grams at birth.

2. Mother's age at the time of birth, represented by three dunmy variables (IMAG, HMAG 35, and HMAG40). Mother's age at the time of birth is considered an endowment measure because relatively older mothers have been found to have a greater frequency of infants in poor health, while relatively young mothers are likely to have "unwanted" births and consequently receive poorer prenatal care.

11 As mentioned in section I, a number of the health and development endowment measures which are treated here as exogenous would be considered endogenous in a more fully specified model. 
TABLE 1

Definition of Variables

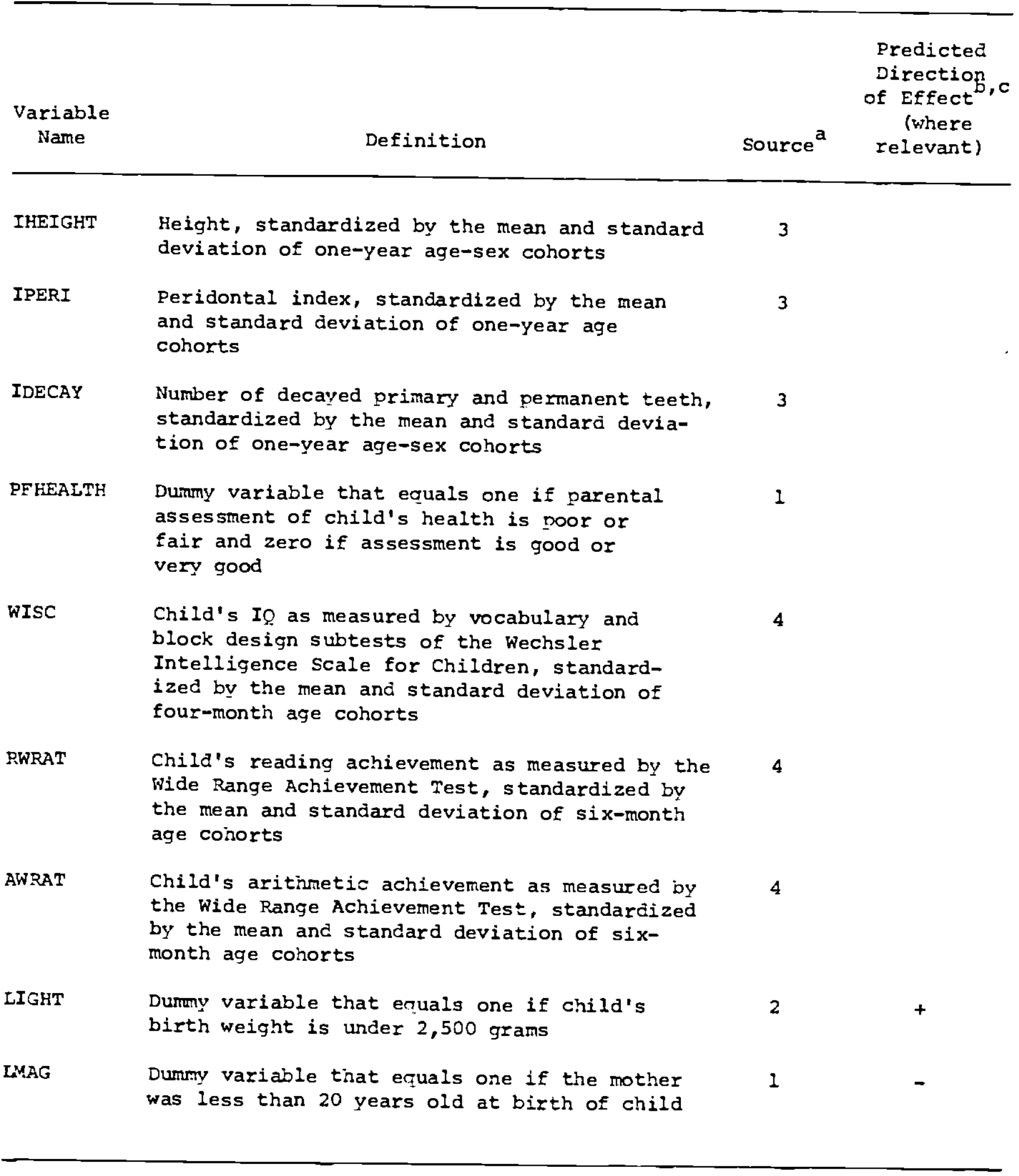


TABLE 1 (continued)

\begin{tabular}{|c|c|c|c|}
\hline $\begin{array}{l}\text { Variable } \\
\text { Name }\end{array}$ & Definition & Source ${ }^{a}$ & $\begin{array}{l}\text { Predicted } \\
\text { Direction } \\
\text { of Effect }, c \\
\text { (where } \\
\text { relevant) }\end{array}$ \\
\hline HMAG 35 & $\begin{array}{l}\text { Durmiy variable that equals one if the mother } \\
\text { was more than } 35 \text { years old at birth of child }\end{array}$ & 1 & \pm \\
\hline HVAG 40 & $\begin{array}{l}\text { Dumny variable that equals one if the mother } \\
\text { was } 40 \text { years old or more at birth of child }\end{array}$ & $I$ & - \\
\hline FYPH & $\begin{array}{l}\text { Dummy variable that equals one if child's } \\
\text { health at one year was poor or fair, and } \\
\text { zero if it was good }\end{array}$ & 1 & - \\
\hline MBEED & $\begin{array}{l}\text { Dumny variable that equals one if the child } \\
\text { was breast-fed }\end{array}$ & $I$ & + \\
\hline IHEAR & $\begin{array}{l}\text { Dumn variable that equals one if hearing } \\
\text { is abnormal and zero otherwise }\end{array}$ & 3 & - \\
\hline$A B N$ & $\begin{array}{l}\text { Dummy variable that equals one if the physi- } \\
\text { cian finds a "significant abnormality" in } \\
\text { examining the child (other than an abnomal- } \\
\text { ity resulting from an accident or injury) }\end{array}$ & 3 & - \\
\hline SEEG & $\begin{array}{l}\text { Dumry variable that equals one if binocular } \\
\text { distance vision is abnormal and child } \\
\text { usually wears glasses }\end{array}$ & 3 & \pm \\
\hline NSEEG & $\begin{array}{l}\text { Duruny variable that equals one if binocular } \\
\text { vision is normal and child usually wears } \\
\text { glasses }\end{array}$ & 3 & \pm \\
\hline SEENG & $\begin{array}{l}\text { Dummy variable that equals one if binocular } \\
\text { vision is abnormal and the child does not } \\
\text { wear glasses }\end{array}$ & 3 & - \\
\hline MEDUCAT & Years of formal schooling completed by mother & 1 & \pm \\
\hline FEDUCAT & Years of formal schooling completed by father & $I$ & \pm \\
\hline ELANG & $\begin{array}{l}\text { Dummy variable that eouals one when a foreign } \\
\text { language is spoken in the home }\end{array}$ & 1 & \pm \\
\hline
\end{tabular}


TABLE I (continued)

\begin{tabular}{|c|c|c|c|}
\hline $\begin{array}{l}\text { Variable } \\
\text { Name }\end{array}$ & Definition & Source ${ }^{a}$ & $\begin{array}{l}\text { Predicted } \\
\text { Direction } \\
\text { of Effect }, c \\
\text { (where } \\
\text { relevant) }\end{array}$ \\
\hline FIRST & $\begin{array}{l}\text { Dummy variable that equals one if child is } \\
\text { the first born in the family }\end{array}$ & 1 & + \\
\hline TWIN & $\begin{array}{l}\text { Dummy variable that equals one if child is } \\
\text { a twin }\end{array}$ & 1 & - \\
\hline $\begin{array}{l}\text { NEAST } \\
\text { MWEST } \\
\text { SOUTH }\end{array}$ & $\begin{array}{l}\text { Dummy variables that equal one if child lives } \\
\text { in Northeast, Midwest, or South, respectively }\end{array}$ & 1 & \pm \\
\hline $\begin{array}{l}\text { URB1 } \\
\text { URB2 } \\
\text { URB3 } \\
\text { NURB }\end{array}$ & $\begin{array}{l}\text { Duruny variables that equal one if child lives } \\
\text { in an urban area with a nopulation of } 3 \text { mil- } \\
\text { lion or more (URBl); in an urban area with a } \\
\text { population between } 1 \text { million and } 3 \text { million } \\
\text { (URB2); in an urban area with a population } \\
\text { less than } 1 \text { million (URB3); or in a non- } \\
\text { rural and non-urbanized area (NURB); omitted } \\
\text { class is residence in a rural area }\end{array}$ & 1 & \pm \\
\hline $\begin{array}{l}\text { MWORKPI } \\
\text { MFORKFT }\end{array}$ & $\begin{array}{l}\text { Dumny variables that equal one if the mother } \\
\text { works part-time or full-time, respectively }\end{array}$ & 1 & - \\
\hline KIND & $\begin{array}{l}\text { Dummy variable that equals one if child at- } \\
\text { tended kindergarten or nursery school }\end{array}$ & 1 & \pm \\
\hline
\end{tabular}


TABLE I (concluded)

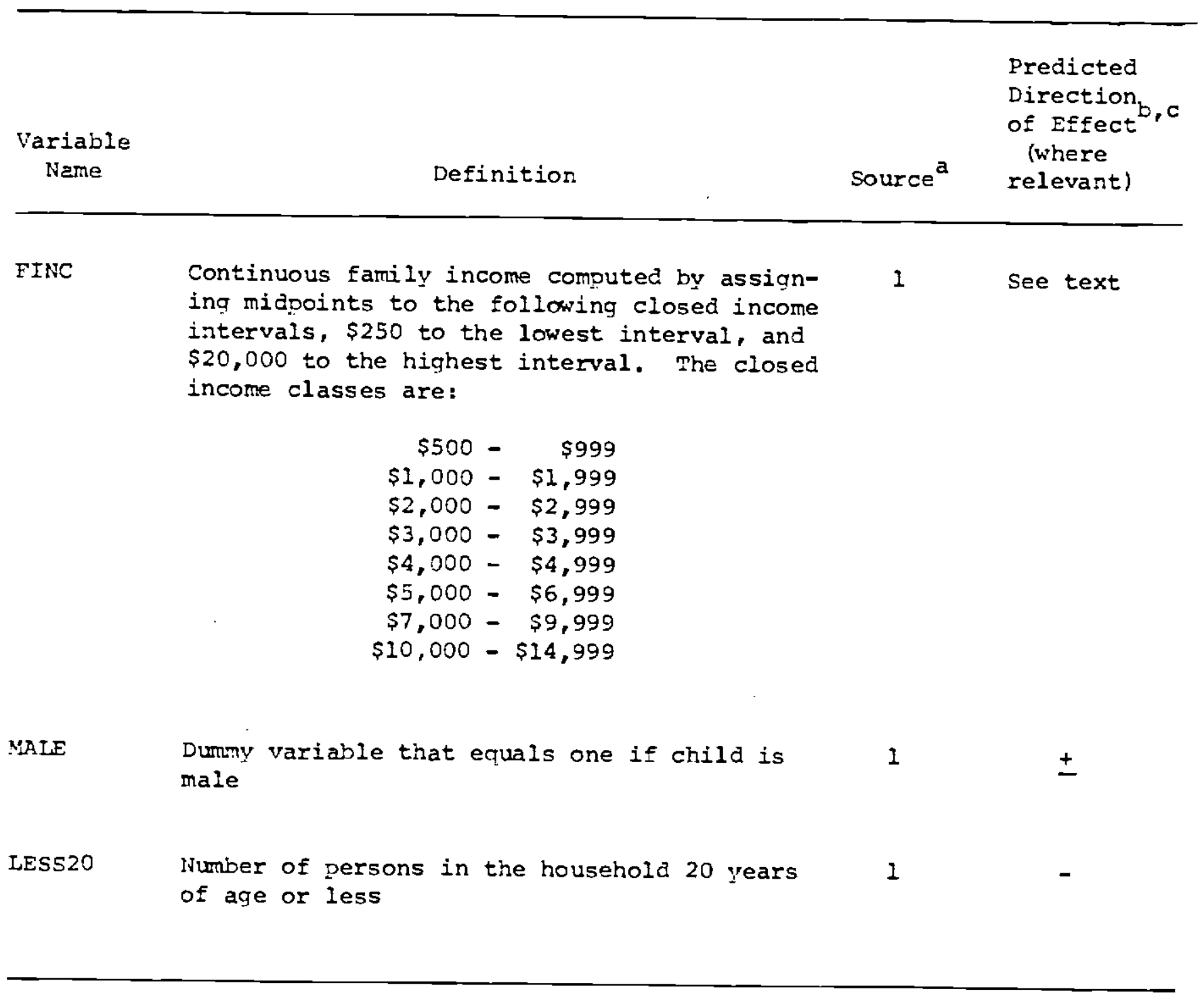


Footnotes to TABLE 1

$a_{T}$ The sources are 1 = medical history form completed by parent, 2 = birth $5=$ school form.

$b_{A}$ effect on a positive variable is expected to have a positive a negative sign means a corresponding cold or intellectual development; a negative sign means a corresponding predicted negative effect.

In effects of prol it is difficult to make predictions about the directions of sideration is that an incroasent, efficiency, and input prices. One conlower efficiency in the production a health endowment, for example, might so, investment would tend tuction function of investment in health. If increase, remain constant, or fall, while the final stock of health might most of the proxies are correlated with A second consideration is that endowments, health and development with both health and development input prices. Given that cross efficiency, or health and develooment input price effects cannot be signed measures also cannot be predicted a prioriori, the effects of these proxy based on two assumptions: (1) the signs in the table are (2) the cross effect does not outweigh the own effect if is positive, and opposite directions.

d

Subject to the modifications in note $c$, the effect of MEDUCAT or FEDUCAT would be positive if the price of time were held constant and ambiguous if
it were not. 
3. The child's health at one year, measured by a dumy variable indicating the parents' assessment of the child's health at one year (denoted FYPH).

4. Whether or not the child was breast-fed (denoted MBFED).

5. Hearing acuity, measured by a dicnotomous variabie that indicates whether or not the child has normal nearing in his best ear (denoted IHEAR). 12

6. Overall diagnostic impressions of the physician concerning whether or not the child had any "significant abnormalities." Our variable (ABN) is a dumny variable that takes the value one when such abnormalities are present. 13

7. Visual acuity, measured by a set of dumny variables indicating whether or not the crild has poor vision ${ }^{14}$ and if

12 A child is defined here to have "normal" hearing if the average threshold decibel reading of the child in his best ear over the range of 500, 1,000 , and 2,000 cycles per second (c.0.s.) is 15 or lower. 500, 1,000, and 2,000 c.p.s. are the frequencies that occur most frequently in normal speech. A tireshold of less than 15 decibels above audiometric zero at these frequencies is classified as corresnonding to "no significant difficulty with faint speech" by the Comittee on Conservation of Hearing of the American Academy of Ophthalmology and Otolaryngology (NCHS 1970a).

${ }^{13}$ In defining $A B N$, we exclude abnormalities resulting from accidents or injuries because these cannot be treated as endowments. The remaining abnormalities are classified as heart disease (congenital or acquired); neurological, muscular, or joint conditions; other congenital abnormalities; and other major diseases.

14 In Cycle II the children were examined without glasses. A child is defined here to have "normal" binocular vision if his or her binocular distance acuity is $20 / 30$ or better (NCHS 1972a). 
it has been corrected (SEEG, NSEEG, SEENG). Although, strictly speaking, information about the correction of visual defects cannot be included in an endowment variable, such information does provide some evidence about the price of medical care, one of our other explanatory variables.

The development endowment is represented by the following variables:

1. Mother's and father's educational attainment (denoted MEDUCAT and FEDUCAT, respectively). Parents' educational attainment is a crude proxy measure of the child's inherited intelligence.

2. A dumny variable indicating whether or not a foreign language is spoken in the home (denoted FLANG). This factor could contribute either positively or negatively to the child's intellectual endowment.

3. Two dumny variables measuring aspects of birth order--one indicating whether the child is the first born in the family (denoted FIRST) and one indicating if the child is a twin (denoted TWIN). Everything else equal, more parental time is available to first born children and non-twins than to later children or twins.

4. Birth weight as defined above. Since birth weight is partially detemined by maternal health and nutrition during pregnancy, it is frequently used as a crude index of overall fetal development (including brain development). 15

15

See Birch and Gussow (1970). Another aspect of educational endowment is publicly-supplied school guality. In future work we hope to supplement the data with measures of school quality. 
5. Visual and hearing acuity, as defined above.

Efficiency in the production of both types of children's human capital is measured by the parents' educational attainment (reDUCAT and FEDUCAT). 16 Since mothers traditionally spend more time with children than do fathers, MEDUCAT should have a greater effect in the reduced form equations than FEDUCAr (as measures solely of inherited Io, they would be expected to have equal effects).

Information about the prices of the inputs in the health and development production functions is difficult to obtain for the Cycle II data set. There are no direct measures of relevant prices such as the price of medical care or the price of parents ' time (or their wage rates). Moreover, since the precise locality of each observation cannot be identified, it is not possible to estimate these prices with local market data. Therefore, we use a set of crude proxy variables to control partially for these prices.

To control for price variation due to region and size of place of residence, we enter a set of three region dumy variables (denoted NEAST, MWEST, SOUTH) and four sizes of place variables (denoted URB1, URB2, URB3, NURB). Information about whether or not the child's vision has been corrected (SEEG, NSEEG) provides some indication of the orice of medical care. To hold constant the cost of the mother's time (probably one of tine most important inputs in both the health and development functions), we control for the primary activity of the mother (full-time work, part-time work, or no

${ }^{16}$ The literature on household production functions commonly treats parental education as an efficiency variable. 
work, denoted by the dumny variables MWORKFT and MWORKPT). Everything else equal, mothers with higher opportunity costs are more likely to work in the labor market (and to work longer hours). ${ }^{17}$ The cost of time, both of mothers who work and those who do not, might also be related to their schooling (MEDUCAT). 18 A similar comment applies with respect to the correlation between the father's price of time and his schooling (FEDUCAT). The final input price proxy is a dumny variable that indicates whether the child attended kindergarten or nursery school (denoted KIND). We assume that the likelihood of kindergarten attendance is negatively related to the price of this type of schooling and positively related to the value of the mother's time.

Family income is represented by FINC, a continuous income variable computed by assigning midpoints to the income classes reported in Cycle II. ${ }^{19}$

Finally, two additional variables are included. The first, a dummy variable incicating whether or not the child is male (denoted MAIE), holds

17 tail by Gronau (1974). We have information on the primary discussed in demother at the time of the survey, but do not know how many activity of the worked. The latter factor might be related in part to the mother's age at
the birth of the child.

18 See Heckman (1974) for evidence that the mother's potential market wage rate and the "shadow value" of her time are positively related to her school-
ing.

${ }^{19}$ Since this family income measure does not hold constant the mother's labor force status and the father's experience, we experimented with an income measure that held these two factors constant. The adjusted income variabile was very highly correlated with FINC (the correlation coefficient was greater than .99) and the regression results were not altered when adjusted income was used in place of FINC. Therefore, we report results based only on the use of FINC in this paper. 
constant possible sex differences in parents' desired child quality ${ }^{20}$ and is included when estimates are reported for both sexes combined. The second is a measure of family size (denoted LEss20). 21 although our model does not call for the latter variable in the reduced form (it is simultaneously determined with child quality), it is among our explanatory variables for the following reason. Family size is not determined with perfect certainty. The resulting random variations in the actual number of children will generate adjustments in final child quality. For example, when a family has more than the desired number of children, this increases the relative price of child quality and leads to a downward adjustment in desired child quality. 22 Thus, we expect children in large fanilies to have lower $\mathrm{H}$ and $\mathrm{D}$.

Tha above variable definitions are summarized in Table 1, along with predicted variable effects in the reduced form. Means and standard deviations of the variables are shown in Table 2.

C. Estimation Method

The relationship summarized by equations (9) and (11) or (10) and

(12) can be written as:

${ }^{20}$ See Ben-Porath and Welch (1976) for a discussion of this possibility. 21. LEss20 does not measure completed family size, but rather the number of persons in the household younger than 20 years at the time of the cycle II interview. Therefore, LESS20 may overstate or understate completed family size. The mean value of LESS20 in our sample (3.6) may seem high, but it must be remembered that this figure is computed from a sample of children, not from a sample of families. In general the mean cormuted from a sample of children will be larger than that computed from a sample of families for two reasons. First, families with no children do not appear in a sample of children, but they do appear in a sample of families. second, anong families with children, the probability of any family being represented in a sample of children is greater the more children in the family, whereas the probability of any family being represented in a sample of families is independent of the number of children in that family.

${ }^{22}$ See Becker and Lewis (1973). 
TABLE 2

Means and Standard Deviations of Dependent and Independent Variables, Whites, Ages 6-11, Mother and Father Present $(N=3608)$

\begin{tabular}{|c|c|c|}
\hline Variable & Mean & $\begin{array}{l}\text { Standard } \\
\text { Deviation }\end{array}$ \\
\hline IHEIGHT & .0456 & .9680 \\
\hline IPERI & -.0394 & .9831 \\
\hline IDECAY & -.0651 & .9677 \\
\hline PFHEALTE & .0424 & .2015 \\
\hline WISC & 103.1951 & 13.9566 \\
\hline RWRAT & 103.0055 & 13.7343 \\
\hline AWRAT & 102.8672 & 13.1335 \\
\hline LIGHT & .0538 & .2256 \\
\hline LMAG & .0696 & .2545 \\
\hline HMAG 35 & .1045 & .3059 \\
\hline EMAG40 & .0310 & .1735 \\
\hline FYPH & .0840 & .2774 \\
\hline MBFED & .3007 & .4586 \\
\hline IHEAR & .0058 & .0761 \\
\hline$A B N$ & .0030 & .0550 \\
\hline SEEG & .0710 & .2568 \\
\hline NSEEG & .0432 & .2034 \\
\hline SEENG & .0482 & .2143 \\
\hline
\end{tabular}

(continued on next page) 


$$
\text { II }-19
$$

TABLE 2 (concluaied)

\begin{tabular}{|c|c|c|}
\hline Variable & Mean & $\begin{array}{l}\text { Standard } \\
\text { Deviation }\end{array}$ \\
\hline MEDUCAT & 11.2406 & 2.7510 \\
\hline FEDUCAT & 11.2650 & 3.4470 \\
\hline ELANG & .1020 & .3027 \\
\hline FIRST & .2894 & .4535 \\
\hline TWIN & .0233 & .1508 \\
\hline NEAST & .2384 & .4261 \\
\hline MWEST & .3276 & .4694 \\
\hline SOUTH & .1768 & .3816 \\
\hline URBI & .1971 & .3978 \\
\hline URB2 & .1256 & .3314 \\
\hline URB 3 & .1815 & .3855 \\
\hline NURB & .1502 & .3573 \\
\hline MWORKPI & .1375 & .3444 \\
\hline IWORKFT & .1375 & .3444 \\
\hline KIND & .7306 & .4437 \\
\hline FINC $^{a}$ & 7.8277 & 4.4149 \\
\hline MALE & .5116 & .4999 \\
\hline LESS2O & 3.6159 & 1.6371 \\
\hline
\end{tabular}

ahousands of dollars. 


$$
\begin{aligned}
& y_{j}=\alpha_{1}+\beta_{1} x_{j}+u_{1 j}, \quad j \text { a member of Regime } 1 \\
& y_{j}=\alpha_{2}+\beta_{2} x_{j}+u_{2 j}, \quad j \text { a member of Regime } 2,
\end{aligned}
$$

where $j$ ranges from 1 to $n$. In (13), $y_{j}$ represents the $j^{\text {th }}$ observation on either of the dependent variables, $x_{j}$ represents the $j^{\text {th }}$ vector of observations on the independent variables, $\alpha_{1}$ and $\alpha_{2}$ are constant terms, $B_{1}$ and $B_{2}$ are vectors of coefficients, and $u_{1 j}$ and $u_{2 j}$ are independent, normally distributed error terms with zero means and identical variances. ${ }^{23}$ The two regimes are defined by the solvency constraint on the financial bequest: Regime 1 denotes the set of observations for which the constraint is effective $\left(B_{j}=0\right)$ and Regime 2 denotes those observations for which the constraint is ineffective $\left(B_{j}>0\right)$. In this context, the major predictions of Section $I$ are restated as follows: $\alpha_{1}$ and $\beta_{1}$ are different from $\alpha_{2}$ and $\beta_{2}$; and the element of $\beta_{1}$ that is the coefficient of income will be positive while the corresponding element of $B_{2}$ will be zero. 24

23

We overlook the dichotomous nature of one of the dependent variables (PFHEAITH). In principle an appropriate transformation, such as a logit transformation, should be introduced here, but we have not done so in the
results reported in section III.

24

With respect to coefficients of variables other than income, our model predicts differences between regimes but does not identify the regime in which the effect will be larger. Even if we had enough additional information to make predictions about relative magnitudes (see Section I, note 21), these predictions might be altered by the possibility that our measures of health and intellectual development are nonlinear transformations of the theoretical variables, $H$ and $D$. Note, however, that this measurement problem does not alter the prediction concerning the effects of income Edwards and Grossman (1976). 
Estimation of equation (13) would be straightforward if we could identify which observations belong in each of the two regimes. 25 In our data, however, there is no direct vay to do so. An alternative procedure would be to estimate $B$ (which from Figure 1 can be seen to depend on those factors which determine the location of the demand and marginal cost curves of children's quality) and use the estimated value of $B$ to classify observations. But again, this procedure requires information about the value of $B$, at least for a subset of observations. Another tactic is to note that among the determinants of $B$, it seems likely that variations in income will cause the greatest amount of variation in $B$. This suggests the simple, though admittedly crude, procedure of classifying observations by fanily income. 26

We estimate the relations in equation (13) using this simple classification scheme. The two subsamples are children whose families have an annual income of under $\$ 7,000$ and those whose families have an annual income of $\$ 7,000$ or more. Although $\$ 7,000$ is not the most obvious cutoff point to use to identify the regimes, ${ }^{27}$ we use it for

25 Even in

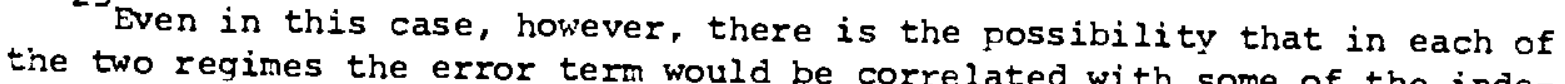
pendent variables, leading to biased point in the context of the estimation coefficient estimates. For a similar tions for women who work and women tions for women who work and women who do not work, see willis (1973).

26

The appropriate estimation procedure for this type of two-regime model in the absence of direct information for classifying observations into regimes is the "switching of regimes" model described in Goldfeld and quandt (1973). The application of this statistical model to our estimation problem is discussed in Edwards and Grossman (1976). We do not use this technique here because it is very expensive.

${ }^{27}$ Lansing and Sonquist (1969) find that about 30 percent of families receive an inheritance. If this same percentage were applied to our sample this would imply an income cutoff somewnere in the $\$ 7,000$ to $\$ 10,000$ interval (47 percent of our sample has family income of $\$ 7,000$ or more and 22 percent has family income of $\$ 10,000$ or more). Such a cutoff would be infeasible
with our data set. 
several reasons. First, this cutoff point separates our data into two roughly equal subsamples, so that standard errors of coefficient estimates in each regime will not differ due to differences in samole sizes. Second, since our observations consist of families with young children, the current income of these families is likely to understate their lifetime wealth (relative to the population at large). If one takes account of this understatement, the top 50 percent of our sample may correspond to the top, say, 40 percent of the population at large. Third, preliminary estimates of equation (13) using, alternately, observations with annual income greater than or equal to $\$ 7,000$ and those with annual incomes greater than or equal to $\$ 10,000$ showed that the coefficient estimates for these two subsamples do not greatly differ (although, of course, their standard errors are larger for the higher income class). Finally, many persons are interested in the behavior of low income groups, and public policy often is aimed at these groups. Hence, we choose a $\$ 7,000$ cutoff point because estimates derived from the resulting pair of income classes will be more useful for policy-makers in the fields of children's health and intellectual development than those derived from a $\$ 10,000$ cutoff point.

Means and standard deviations of all variables in each of the two subsamples are shown in Table 3. A cursory examination of this table reveals that there are indeed important differences between these tiwo groups with respect to both the dependent and independent variables. 
TABLE 3

Means and Standard Deviations of Dependent and Independent Variables, Writes, Ages 6-11, Mother and Father Present

\begin{tabular}{|c|c|c|c|c|}
\hline \multirow[b]{2}{*}{ Variable } & \multicolumn{2}{|c|}{ Income $<\$ 7,000^{a}$} & \multicolumn{2}{|c|}{ Income $\geq \$ 7,000^{\mathrm{b}}$} \\
\hline & Mean & $\begin{array}{l}\text { Standard } \\
\text { Deviation }\end{array}$ & Mean & $\begin{array}{l}\text { Standard } \\
\text { Deviation }\end{array}$ \\
\hline IHEIGHT & -.0869 & .9687 & .1896 & .9468 \\
\hline IPERI & .0790 & 1.1126 & -.1681 & .8002 \\
\hline IDECAY & .1226 & 1.0750 & -.2691 & .7866 \\
\hline PFHEALTH & .0580 & .2338 & .0254 & .1575 \\
\hline WISC & 99.3097 & 13.0889 & 107.4176 & 13.6436 \\
\hline RWRAT & 99.6754 & 13.7437 & 106.6246 & 12.7786 \\
\hline AWRAT & 100.1884 & 13.6789 & 105.7785 & 11.8497 \\
\hline LIGHT & .0596 & .2368 & .0474 & .2126 \\
\hline IMAG & .0963 & .2951 & .0405 & .1972 \\
\hline HMAG 35 & .1043 & .3057 & .1074 & .3062 \\
\hline LNLAG4O & .0362 & .1868 & .0254 & .1575 \\
\hline EYPH & .0963 & .2951 & .0706 & .2562 \\
\hline MBEED & .3092 & .4623 & .2915 & .4546 \\
\hline IHEAR & .0075 & .0860 & .0040 & .0635 \\
\hline ABIN & .0043 & .0651 & .0017 & .0416 \\
\hline SEEG & .0553 & .2287 & .0879 & .2832 \\
\hline NSEEG & .0431 & .2030 & .0434 & .2038 \\
\hline SEENG & .0442 & .2055 & .0526 & .2234 \\
\hline
\end{tabular}


TABLE 3 (concluded)

\begin{tabular}{|c|c|c|c|c|}
\hline \multirow[b]{2}{*}{ Variable } & \multicolumn{2}{|c|}{ Income $<\$ 7,000^{\mathrm{a}}$} & \multicolumn{2}{|c|}{ Income $\geq \$ 7,000^{\mathrm{b}}$} \\
\hline & Mean & $\begin{array}{l}\text { Standard } \\
\text { Deviation }\end{array}$ & Mean & $\begin{array}{l}\text { Standard } \\
\text { Deviation }\end{array}$ \\
\hline MEDUCAT & 10.1985 & 2.7935 & 12.3730 & 2.2027 \\
\hline FEDUCAT & 9.7286 & 3.2953 & 12.9346 & 2.7647 \\
\hline FLANG & .1251 & .3309 & .0769 & .2665 \\
\hline FIRST & .2869 & .4524 & .2921 & .4548 \\
\hline THIN & .0165 & .1274 & .0307 & .1724 \\
\hline NEAST & .1937 & .3953 & .2869 & .4524 \\
\hline HWEST & .3225 & .4676 & .3331 & .4715 \\
\hline SOUTH & .2342 & .4236 & .2145 & .3185 \\
\hline URBI & .1346 & .3414 & .2649 & .4414 \\
\hline URB 2 & .0793 & .2703 & .1758 & .3808 \\
\hline URB3 & .1703 & .3760 & .1938 & .3954 \\
\hline INURB & .1799 & .3842 & .1180 & .3227 \\
\hline MWORKPT & .1426 & .3498 & .1319 & .3384 \\
\hline ?NORKFT & .1213 & .3266 & .1550 & .3620 \\
\hline KIND & .6275 & .4836 & .8427 & .3642 \\
\hline FINC $^{C}$ & 4.6281 & 1.6811 & 11.3048 & 3.7928 \\
\hline MALE & .4944 & .5001 & .5304 & .4992 \\
\hline LESS20 & 3.8302 & 1.7639 & 3.3829 & 1.4523 \\
\hline
\end{tabular}

\footnotetext{
$a_{1879}$ observations.

b1729 observations.

$\mathrm{C}_{\text {Thousands of dollars. }}$
} 


\section{Results}

Ordinary least squares estimates of the reduced form equations for the dependent variables WISC, RWRAT, AWRAT, IHEIGHT, IPERI, IDECAY, and PFHEALTH for each income class annear in Tables $A-1$ through $A-7$ in the Appendix. In discussing these results we focus first on the basic hypotheses generated by the theoretical model and second on specific findings concerning the effects of the explanatory variables and how these effects differ for the two income classes. Ill of our equations are estimated for males and females separately as well as for both sexes pooled. Only the pooled results are discussed in detail, however, because coefficient estimates were not found to differ significantly by $\operatorname{sex}^{1}$

\section{A. Basic Hvpotheses}

There are two primary oredictions qenerated by the model: the sets of coefficients in the two reqimes will differ; and the family income variable will have a positive effect in Regime 1 and no effect in Regime 2. There is also the more fundamental prejiction that the set of explaratory variables suggested by the model do succeed in explaining a significant portion of the variance in tine health and development variables. The latter prediction is clearly supported by our results. Adjusted $\mathrm{R}^{2}$ 's range from a high of .238 (for WISC in the lower income class) to a low of .025 (for IHEIGHT in the upper income class). Even

\footnotetext{
${ }^{1}$ Estimates by sex are shown in Tables $A-B$ through $A-14$.
} 
the lowest of these $R^{2}$ 's is statistically significant at the 1 percent level of significance. Thus, even though the explanatory variables are in some cases imperfect proxies for the desired tineoretical variables, taken as a set they do have a significant impact on our health and development measures.

The prediction of two distinct regimes or two different relationships between each of owr health and development variables and the set of explanatory variables is also generally supported by our results (see Table 4). ${ }^{2}$ Statistically significant differences in the sets of cofficients for the two income classes are reported for RWRAT, AWRAT, IHEIGHT, IDECAY, and PFHEALTH. Only for IPERI and WISC are the differences in coefficients not significant. Although these results cannot be characterized as "unanimous" support for the basic structure of our model, they do constitute stronger verification than may be initially apparent. The two income classes used here are unlikely to coincide completely with the two regimes specified by the model. The resulting misclassification of observations will tend to bias the coefficient in the two income classes towards equality, making it more difficult to obtain significantly different coefficients in the two income classes even though such differences do exist in the two regimes. We observe

2 The "F" tests presented here cannot prove the validity of our model because there are alternative explanations for finding significant differences between coefficients in the two regimes. For example, the true relationship between $H$ (or D) and the set of explanatory variables could be identical in the two regimes, but different estimates still could be generated if our proxy measures of $H$ (or D) are nonlinear
transformations of its true value. 
TABLE 4

\begin{tabular}{|c|c|}
\hline $\begin{array}{l}\text { Dependent } \\
\text { Variable }\end{array}$ & $E_{30,3548}$ \\
\hline WISC & 1.31 \\
\hline RWRAT & 1.62 \\
\hline AWRAT & 2.02 \\
\hline IHEIGHT & 1.54 \\
\hline IPERI & 1.33 \\
\hline IDECAY & 2.00 \\
\hline PFHEALTH & 2.10 \\
\hline
\end{tabular}

${ }^{a}$ Critical value for $F_{30,1000}$ is 1.47 at the 5 percent level of significance. 
significant differences in coefficients for five of our seven variables despite this bias towards finding no such difference.

The final prediction of our model--that income will have a positive effect on health or development for families in Regime 1 lour lower income class) and no effect in Regime 2 (our upper income class)--does not receive strong support in our results. Even though the income coefficients are uniformly lower in the upper income class than in the lower income class, only for the two achievement measures (AWRAT and RWRAT) do we observe the predicted pattern of income coefficients (see Table 5). For both of these dependent variables, income has a positive, significant impact for lower income families and a nonsignificant impact for upper income families. For the other dependent variables, family income is either statistically significant in both income classes (WISC, IPERI, and IDECAY) or in neither income class (IHEIGHT and PFHEALTH).

One likely explanation for the significant coefficients in the upper income class is the previously mentioned bias resulting from the misclassification of observations. In particular, it is likely that members of Regime 1 are erroneously included in the over $\$ 7,000$ income class, causing an upward bias in the coefficient of FINC for that class. The plausibility of this explanation is confirmed by an additional test. In the upper income class we replace the continuous income variable FINC with two dummy variables indicating whether the family had income of $\$ 10,000$ and over, or of $\$ 15,000$ and over. These dummy variables allow for a nonlinear income effect in the upper income class. In no case was income found to have a significant marginal effect when it exceeded 
TABLE 5

Regression Coefficients of Family Income ${ }^{a}$

\begin{tabular}{|c|c|c|}
\hline \multirow{2}{*}{$\begin{array}{l}\text { Denendent } \\
\text { Variable }\end{array}$} & Income $<\$ 7,000$ & \multirow{2}{*}{$\frac{\text { Income } \geq \$ 7,000}{\text { FINC }}$} \\
\hline & FINC & \\
\hline WISC & $\begin{array}{r}.762 \\
(15.94)\end{array}$ & $(8.01)$ \\
\hline RWRAT & $\begin{array}{r}.712 \\
(11.61)\end{array}$ & $\begin{array}{r}.035 \\
(0.18)\end{array}$ \\
\hline AWRAT & $\begin{array}{r}1.018 \\
(22.99)\end{array}$ & $\begin{array}{r}.087 \\
(1.25)\end{array}$ \\
\hline IHEIGHT & $\begin{array}{r}.017 \\
(1.18)\end{array}$ & $(0.43)$ \\
\hline IPERI & $\begin{array}{c}-.033 \\
(3.45)\end{array}$ & $\begin{array}{c}-.011 \\
(4.53)\end{array}$ \\
\hline IDECAY & $\begin{array}{r}-.067 \\
(16.44)\end{array}$ & $\begin{array}{r}-.019 \\
(12.94)\end{array}$ \\
\hline PFHEALTH & $\begin{array}{c}-.006 \\
(2.47)\end{array}$ & $\begin{array}{c}-.0002 \\
(0.03)\end{array}$ \\
\hline
\end{tabular}

a Source: Appendix, Tables Al - A7. F statistics in parentheses. The critical $F$ value at the 5 percent level of significance is 2.69 on a one-tailed test. 
$\$ 15,000$; and only for WISC and IDECAY did income have a significant marginal effect when it exceeded $\$ 10,000$. Thus, for those observations in the upper income class which have higher incomes--the very observations most likely to actually belong in kegime 2--income does not have a significant marginal impact on health and deveiopment.

\section{B. Effects of Other Variables}

In discussing effects of variables other than income on intellectual development and health, we deal with narents' schooling, mother's work status, number of children in the family, health endowments measured in infancy, and health endowments measured currently. ${ }^{3}$ To focus the discussion, note that among our health variables height would be viewed as the best health measure by persons concerned with the relationshin between health output and proper nutrition (for example, National Center for Health Statistics 1970b, 1975; Seoane and Latham 1971; Owen 1973). The peridontal index and the number of decayed primary and permanent teeth are good overall indexes of oral health and supplementary measures of nutrition. It is plausible that the peridontal index, which reflects status of the gums, is less sensitive to appropriate dental care than the number of decaved teeth. This proposition is supported by the higher adjusted $R^{2}$ 's in the decay regressions than in the peridontal regressions. Parental assessment of the child's current state of health is emoloyed as a dependent variable to

\footnotetext{
3 The reader is left to insoect the effects of the following variables: twin status of child, sex of child, foreign lanquage spoken in the home, first born child, and kindergarten or nursery school attendance.
} 
show how results differ when health is measured subjectivelv by parents as opoosed to objectively bu physicians.

Table 6 contains reqression coefficients of mother's schooling and father's schooling. These two variables have positive and statisticallv significant effects on all measures of intellectual develooment in both the high income sample and the low income sample. When health is defined in a positive manner, ${ }^{4}$ fifteen of the sixteen schooling coefficients are positive, but only ten achieve statistical significance at conventional levels of confidence. These ten appear primarily in the low income sample. It is noteworthy that neight, which nutritionists would view as the most important health measure in Table 6 , is practically independent of schooling in the high income samole but dependent unon schooling in the low income sample. We reach the tentative conclusion that schooling effects are more important for low income Eamilies in the case of health but not in the case of intellectual development.

Presumably, schooling of both parents is positively correlated with the endowment, efficiency, and the value of time. Subject to the modification in Table 1 (note $c$ ), an increase in the endowment or in efficiency raises health or development, while an increase in the value of time lowers it. Since we are not able to control fully for the value of time as schooling varies, our results imoly that the efficiency or endowment effect outweighs the value of time effect.

\footnotetext{
4 Recall that IPERI, IDECAY, and PFHEALTH are negative correlates of children's health.
} 
TABLE 6

Regression Coefficients of Mother's Schooling and Father's Schooling ${ }^{a}$

\begin{tabular}{|c|c|c|c|c|}
\hline \multirow{2}{*}{$\begin{array}{l}\text { Dependent } \\
\text { variable }\end{array}$} & \multicolumn{2}{|c|}{ Income $<\$ 7,000$} & \multicolumn{2}{|c|}{ Income $\geq \$ 7,000$} \\
\hline & MEDUCAT & FEDUCAT & MEDUCAT & FEDUCAT \\
\hline WISC & $\begin{array}{r}.909 \\
(49.05)\end{array}$ & $\begin{array}{r}.706 \\
(41.83)\end{array}$ & $\begin{array}{r}.944 \\
(29.91)\end{array}$ & $\begin{array}{r}.574 \\
(16.94)\end{array}$ \\
\hline RWRAT & $\begin{array}{r}.817 \\
(33.13)\end{array}$ & $\begin{array}{r}.665 \\
(30.97)\end{array}$ & $\begin{array}{r}.717 \\
(18.97)\end{array}$ & $\begin{array}{r}.616 \\
(21.52)\end{array}$ \\
\hline AWRAT & $\begin{array}{r}.565 \\
(15.33)\end{array}$ & $\begin{array}{r}.720 \\
(35.11)\end{array}$ & $\begin{array}{r}.684 \\
(19.28)\end{array}$ & $\begin{array}{r}.354 \\
(7.95)\end{array}$ \\
\hline IHEIGHT & $\begin{array}{r}.025 \\
(5.66)\end{array}$ & $\begin{array}{r}.018 \\
(4.16)\end{array}$ & $\begin{array}{c}.012 \\
(0.87)\end{array}$ & $\begin{array}{r}.004 \\
(0.16)\end{array}$ \\
\hline IPERI & $\begin{array}{l}-.023 \\
(3.54)\end{array}$ & $\begin{array}{r}-.032 \\
(10.07)\end{array}$ & $\begin{array}{l}-.005 \\
(0.25)\end{array}$ & $\begin{array}{r}-.017 \\
(4.06)\end{array}$ \\
\hline IDECAY & $\begin{array}{r}-.036 \\
(10.37)\end{array}$ & $\begin{array}{r}-.025 \\
(6.94)\end{array}$ & $\begin{array}{c}-.034 \\
(10.74)\end{array}$ & $\begin{array}{l}-.020 \\
(5.66)\end{array}$ \\
\hline PFHEALTH & $\begin{array}{l}.001 \\
(.33)\end{array}$ & $\begin{array}{l}-.006 \\
(8.44)\end{array}$ & $\begin{array}{l}-.003 \\
(1.46)\end{array}$ & $\begin{array}{l}-.002 \\
(1.78)\end{array}$ \\
\hline
\end{tabular}

a Source: Appendix, Tables Al-A7. F statistics in parentheses. The critical $F$ values at the 5 percent level of significance are 2.69 on a one-tailed test and 3.84 on a two-tailed test. 
There is some evidence in Table 6 that mother's schooling has a larger impact on cognitive development than father's schooling. Five of the six mother's schooling coefficients exceed the corresponding father's schooling coefficients. This is consistent with the notion that mother's schooling is a more important determinant of efficiency in development production than father's schooling. A related and interesting finding emerges when separate development functions are estimated for boys and girls (see Tables $A-8$ through $A-10$ ). In almost all instances, mother's schooling has a larger effect on the intellectual development of girls than of boys. On the other hand, father's schooling has a larger effect on the intellectual development of boys than of girls. We do not know whether this reflects basic properties of the development production function or whether it reflects osychological forces in early childrearing such as the child's attachment to the parent of the same sex.

Table 7 contains regression coefficients of the two variables for mother's work status in the labor force. The signs of twenty-three of the twenty-eight coeficients in the table indicate that children whose mothers work full-time or part-time have lower levels of health and development than children whose mothers do not work. In the development functions only one of six work status effects is significant for the low income sample, while three of six are negative and significant for the high income sample. ${ }^{5}$ In the health functions

5 The coefficient of MWORKPT on RWRAT in the high income sample is positive and significant. 
TABLE 7

Regression Coefficients of Mother's Work Status

\begin{tabular}{|c|c|c|c|c|}
\hline \multirow{2}{*}{$\begin{array}{l}\text { Dependent } \\
\text { Variable }\end{array}$} & \multicolumn{2}{|c|}{ Income $<\$ 7,000$} & \multicolumn{2}{|c|}{ Income $\geq \$ 7,000$} \\
\hline & MWORKFT & MWORKPT & MWORKFT & MWORKPT \\
\hline WISC & $\begin{array}{l}-1.764 \\
(4.46)\end{array}$ & $\begin{array}{r}.566 \\
(0.53)\end{array}$ & $\begin{array}{l}-2.388 \\
(7.55)\end{array}$ & $\begin{array}{r}.190 \\
(0.04)\end{array}$ \\
\hline RWRAT & $\begin{array}{l}-.645 \\
(0.50)\end{array}$ & $\begin{array}{c}-.793 \\
(0.87)\end{array}$ & $\begin{array}{c}-2.234 \\
(7.27)\end{array}$ & $\begin{array}{r}2.383 \\
(7.51)\end{array}$ \\
\hline AWRAT & $\begin{array}{r}-.495 \\
(0.28)\end{array}$ & $\begin{array}{c}-.338 \\
(0.15)\end{array}$ & $\begin{array}{r}-1.760 \\
(5.04)\end{array}$ & $\begin{array}{l}.085 \\
(0.01)\end{array}$ \\
\hline IHEIGHT & $\begin{array}{l}-.110 \\
(2.61)\end{array}$ & $\begin{array}{r}-.227 \\
(12.83)\end{array}$ & $\begin{array}{c}-.072 \\
(1.23)\end{array}$ & $\begin{array}{c}-.095 \\
(1.91)\end{array}$ \\
\hline IPERI & $\begin{array}{r}.080 \\
(1.80)\end{array}$ & $(0.003)$ & $\begin{array}{r}.106 \\
(3.90)\end{array}$ & $\begin{array}{r}.080 \\
(2.03)\end{array}$ \\
\hline IDECAY & $\begin{array}{r}.230 \\
(10.23)\end{array}$ & $\begin{array}{r}.068 \\
(1.04)\end{array}$ & $\begin{array}{r}.188 \\
(13.07)\end{array}$ & $\begin{array}{r}.007 \\
(0.02)\end{array}$ \\
\hline PFHEALTH & $\begin{array}{r}.011 \\
(0.49)\end{array}$ & $\begin{array}{r}.007 \\
(0.25)\end{array}$ & $\begin{array}{l}.005 \\
(0.25)\end{array}$ & $\begin{array}{r}.025 \\
(5.00)\end{array}$ \\
\hline
\end{tabular}

asource: Appendix, Tables Al-A7. F statistics in narentheses. The critical $F$ values at the 5 percent level of significance are 2.69 on a one-tailed test and 3.84 on a two-tailed test. 
about the same number of effects are significant in each sample. While no overall pattern of effects is apparent for the health measures, our results suggest that mother's participation in the labor market has a greater detrimental effect on the children in high income families than on those in low income families. Interpretation of this finding is subject to the caution that unlise other parental characteristics, mother's labor force status changes over the child's early life cycle. Our work status variables provide information only on the primary activity of the mother at the time of the Health Examination Survey. Before firm conclusions can be reached with respect to the role of mother's labor force status in the determination of children's health and development, the effects of length of participation and of the life cycle pattern of participation would also have to be examined.

Regression coefficients of the number of persons in the household 20 years of age or less are presented in Table 8 . This variable serves as a proxy for completed family size. It has negative and statistically significant effects on the three measures of intellectual development. The effects of number of children in the family on health are more erratic. When health is defined in a positive manner, six of the eight regression coefficients are negative, but only four are statistically significant. A striking finding is the importance of family size in the determination of the height of children from low income families and its unimportance in the determination of the height of children from high income families.

When health is measured by height, a consistent pattern of results emerges from Tables 6, 7, and 8. Parents' schooling, mother's work 
TABLE 8

Regression Coefficients of Number of Persons in Household 20 Years of Age or Less ${ }^{a}$

\begin{tabular}{|c|c|c|}
\hline \multirow{2}{*}{$\begin{array}{l}\text { Dependent } \\
\text { Variable }\end{array}$} & Income $<\$ 7,000$ & \multirow{2}{*}{$\frac{\text { Income } \geq \$ 7,000}{\text { LESS20 }}$} \\
\hline & LESS20 & \\
\hline WISC & $\begin{array}{r}-.620 \\
(13.44)\end{array}$ & $\begin{array}{r}-.720 \\
(10.03)\end{array}$ \\
\hline RWRAT & $\begin{array}{r}-.808 \\
(19.03)\end{array}$ & $\begin{array}{r}-.745 \\
(11.82)\end{array}$ \\
\hline AWRAT & $\begin{array}{r}-.354 \\
(3.54)\end{array}$ & $\begin{array}{r}-.468 \\
(5.21)\end{array}$ \\
\hline IHEIGHT & $\begin{array}{r}-.060 \\
(18.92)\end{array}$ & $\begin{array}{r}-.022 \\
(1.63)\end{array}$ \\
\hline IPERI & $\begin{array}{r}.013 \\
(0.72)\end{array}$ & $\begin{array}{r}-.00001 \\
(0.00)\end{array}$ \\
\hline IDECAY & $\begin{array}{r}.027 \\
(3.39)\end{array}$ & $\begin{array}{r}.048 \\
(12.73)\end{array}$ \\
\hline PFHEALTH & $\begin{array}{r}.006 \\
(3.49)\end{array}$ & $\begin{array}{l}-.001 \\
(0.28)\end{array}$ \\
\hline & & \\
\hline
\end{tabular}

asource: Appendix, Tables Al-A7. F statistics in parentheses. The critical $F$ values at the 5 percent level of significance are 2.69 on a one-tailed test and 3.84 on a two-tailed test. 
status, and family size are significant predictor variables of height in the low income sample but not in the high income sample. On the other hand, these three variables tend to be as important (or more important) predictors of development in the high income sample as in the low income sample. A possible explanation of this pattern is that investments in certain kinds of health are subject to more sharply diminising returns than investments in intellectual development. If so, determinants of the marginal cost of investment in health would have relatively small effects in the reduced form demand curve at relatively high levels of health and investment.

Table 9 contains regression coefficients of health endownents measured in infancy. In discussing this set of variables, we focus on the effects of birth weight and breast-feeding on intellectual development. The dunmy variable for birth weight under 2,500 grams or 5 pounds (IIGHT) has significant, negative effects on all measures of development in both high and low income samples. Somewhat surprisingly, absolute effects are larger in the high income samole than in the low income sample. Intuitively, one might expect high income parents to compensate more for the effects of low birth weight than low income parents by making relatively larger investments in the health and inté:lectual development of the poorly endowed child. Subject to some modifications spelled out in section $I$, our finding is consistent with a model in which birth weight is a positive correlate of efficiency in production and a positive correlate of the endowment. 


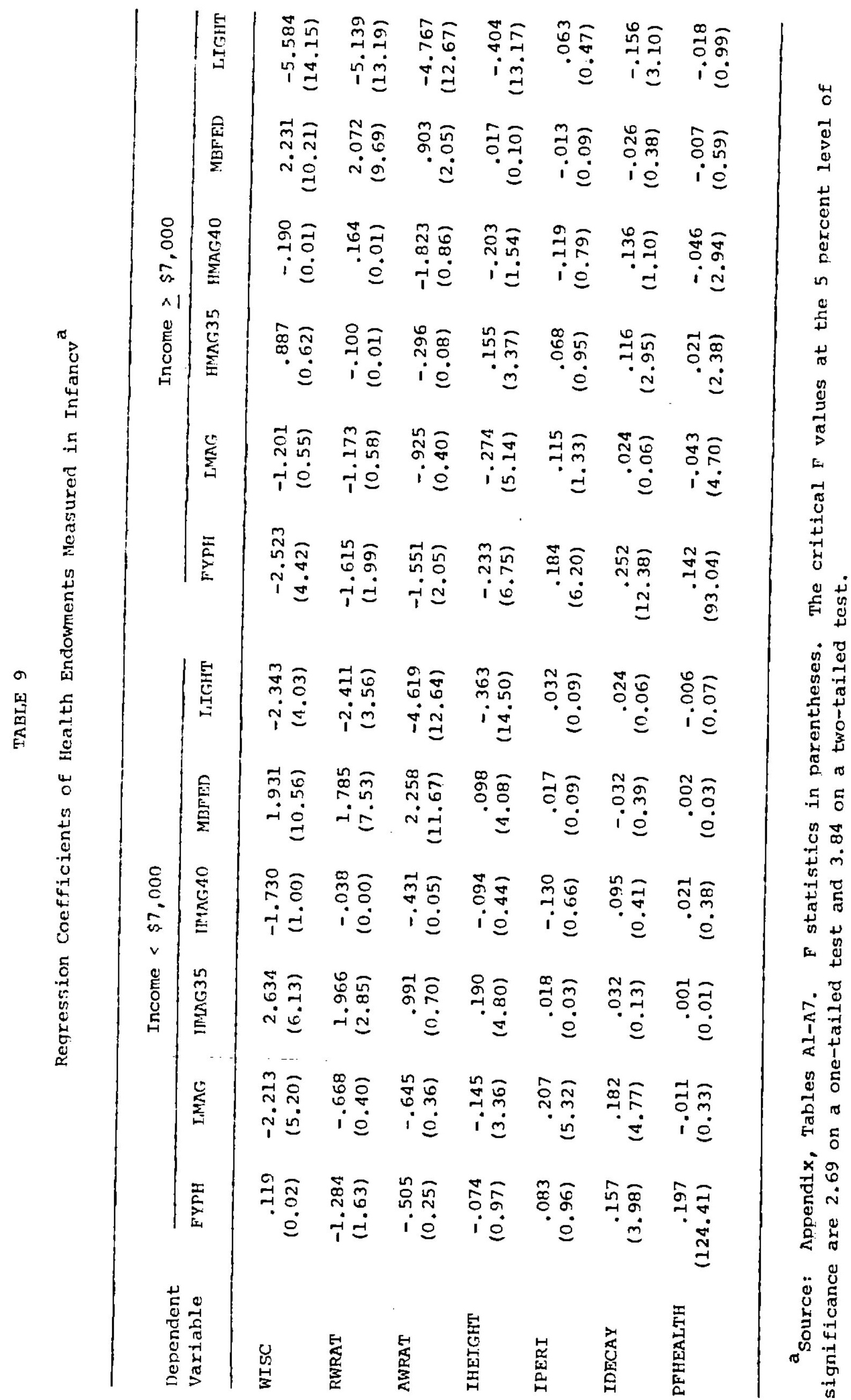


The coefficient of the dummy variable for breast-feeding (MBFED) indicates substantial returns to this activity in terms of cognitive development. While each discipline may offer its own interpretation of this result, a plausible explanation is that MBFED serves as an auxiliary measure of both the amount of time mothers spend with their children and families' tastes for children.

Regression coefficients of health endowments measured currently are presented in Table 10. All of these are based on the physical examinations administered in the Health Examination Survey. Once again we focus on endowment effects in the development functions. All six coefficients of abnormal hearing (IHEAR) are negative, and five of the six are statistically significant. It is not surprising that the impact of poor hearing is larger in the case of school achievement than in the case of IQ. The importance of poor hearing in the determination of school achievement is revealed by the following comparison. In the high income sample, with all other factors held constant, children with poor hearing have a RWRAT score that is approximately 14 points lower than children with normal hearing. This difference is twice as large as the 7 point difference in the mean RWRAT score in the high income sample as compared to the low income sample. The presence of significant abnormalities (ABN) also is detrimental to achievement and $I Q$, although the effects are insignificant in the high income sample. To a large extent, the last result is due to the very low prevalence of abnormalities (.17 percent) in the high income sample.

Strictly speaking the vision variables in Table 10 (SEEG, NSEEG, SEENG) cannot be interpreted as endowments because they combine 


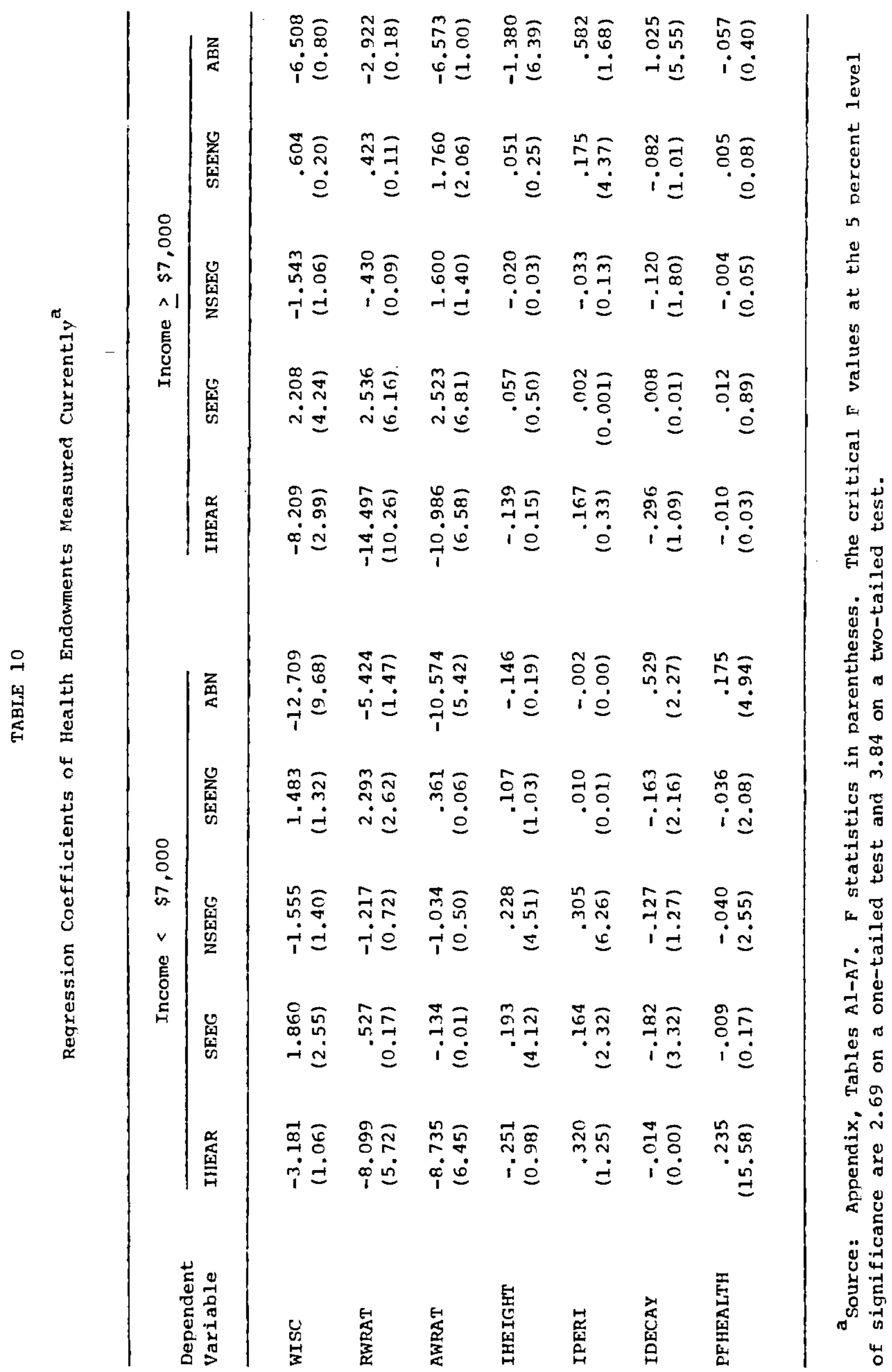


information on uncorrected vision with information on whether the child wears glasses. Nevertheless, these variables convey useful information concerning the impact of investment in vision on intellectual development. 6 In particular, the difference between the coefficient of SEEG and the coefficient of SEENG compares children with abnormal uncorrected vision who wear glasses to children with abnormal uncorrected vision who do not wear glasses. These differences are shown in Table 11. In general investment in improved vision has a positive payoff in terms of intellectual development in the high income sample but not in the low income sample. Kessner (1974) reports that 40 percent of children in a low income sample who were tested with their glasses failed a visual acuity test. It is plausible that this percentage would be much smaller in a high income sample due to the receipt of higher quality optometric services by children in such a sample. If so, this provides an explanation of the results in Table 11 and evidence that the returns to appropriate vision correction might be substantial.

' A similar comment can be made with regard to hearing since children with endowed (uncorrected) abnormal hearing might have had their hearing corrected by investment. Such children cannot be identified in the sample. In the case of vision, since children who wear eyeglasses were examined without them, only endowed (uncorrect) abnomal vision can be identified precisely. Information on the use of eyeglasses was added to the regressions to make the results more comparable to those for poor hearing. Horeover, this procedure controls in part for reverse causality from intellectual development to poor vision due to excessive use of the eyes.

7 The positive and significant coefficients of SEEG in the high income sample indicate that children with abnormal uncorrected vision who wear glasses have higher intellectual development scores than children with normal uncorrected vision who do not wear glasses. This might reflect a negative correlation between SEEG and the price of medical care, or it might reflect reverse causality from development to SEEG. 
TABLE 11

Difference Between Coefficients of SEEG and SEENG in Intellectual Develonment Rearessions

\begin{tabular}{lcc}
\hline $\begin{array}{l}\text { Debendent } \\
\text { Variable }\end{array}$ & $\frac{\text { Income }<\$ 7,000}{\text { Difference }}$ & $\frac{\text { Income } \geq \$ 7,000}{\text { Difference }}$ \\
\hline WISC & .377 & 1.604 \\
RWRAT & -1.766 & 2.113 \\
AWRAT & -.495 & .763 \\
\hline
\end{tabular}




\section{Summary}

A stated goal of public policy in the united states is to improve the economic and social well-being of certain groups of children by improving their cognitive develonment and health. To allocate scarce resources among competing programs with respect to children, policymakers require infornation about the dollar costs and benefits of these programs. Clearly, our results cannot supply policy-makers with all of this information. We have no measures of the costs of raising health or development via alternative programs such as those aimed at reducing the incidence of low birtin weight or lowering completed family size. Hor do we have measures of the dollar values of the benefits of such programs. Nevertheless, our results do contain policy relevant insights about potential benefits in terms of "physical" (health or cognitive development) units. Policy-makers are then free to assign whatever set of weights they choose to these "physical" units and can thereby translate increments in health or development into monetary magnitudes.

Further, our results are useful whether or not the mechanism by which a given variable alters health or development is fully understooc. In the case where the mechanism is known, our results can be used to identify the appropriate kinds of government intervention. A case in point is the theoretical and empirical role of family income. Here we feel confident that the basic force at work is command over real resources provided by income. Alternatively, when effects of certain variables are large but mechanisms are not well understood, our findings 
suggest the nature of additional research that is required to formulate public policy, rather than the appropriate policies per se. Consider for example, our result that parents' schooling is an important determinant of the height of children from low income families. This result has a very definite policy implication if the mechanism at work is a positive correlation between schooling and nutritional intakes or between schooling and knowledge of what constitutes an appropriate diet. The policy implication is much less clearcut if the mechanism at work is a positive relationship between parents' schooling and genetic inheritance.

Our major findings are:

1. The prediction of two distinct regimes or two different relationships between each of our health and development variables and the set of explanatory variables is generally supported by our results. Statistically significant differences in the sets of coefficients for the two income classes are reported for five of seven dependent variables. Although these results cannot be characterized as "unanimous" support for the basic structure of our model, they do constitute stronger verification than may be initially apparent. The two income classes used here are unlikely to coincide completely with the two regimes specified by the model. The resulting misclassification of observations will tend to bias the coefficient in the two income classes towards equality, making it more difficult to obtain significantly different coefficients in the two income classes even though such differences do exist in the two regimes. We observe significant differences in coefficients for five of our seven variables despite this bias towards finding no such difference. 
2. The prediction that income will have a positive effect on health or development for families in Regime 1 and no effect in Regime 2 receives weaker support in our results. For the two achievement measures, income has a positive, significant impact for lower income families and a nonsignificant impact for upper income families. For the other dependent variables, family income is either statistically significant in both income classes or in neither income class. One likely explanation for the significant coefficients in the upper income class is the previously mentioned bias resulting from the misclassification of observations. In particular, it is likely that members of Regime 1 are erroneously included in the over $\$ 7,000$ income class, causing an upward bias in the coefficient of income for that class.

3. When health is measured by height, parents' schooling, mother's work status, and family size are significant predictor variables in the low income sample but not in the high income sample. On the other hand, these three variables tend to be as important (or more important) predictors of intellectual development in the high income sample as in the low income sample.

4. Health endowment and investment measures have significant, positive effects on cognitive development. In particular, cognitive development scores are higher when children weighed more than five pounds at birth, when they were breast-fed, when their current hearing is normal, and when abnormal uncorrected vision is corrected by the use of eyeglasses. These findings suggest that prenatal and pediatric care programs that could identify high risk mothers and children at modest cost would have relatively high expected benefits. 
Finally, our findings highlight at least two fruitful areas for future research. One is an investigation of the extent to which endogenous current health measures affect intellectual development. The second is an investigation of health and development relationships at later stages in the child's life cycle. Both of these will contribute further to our understanding of how health and development interact and will provide more refined measures of benefits from investments in children's health. 
TABLE AI

Ordinary Least Squares Regressions of wisC

Regressions include 3 region and 4 residence dummy variables

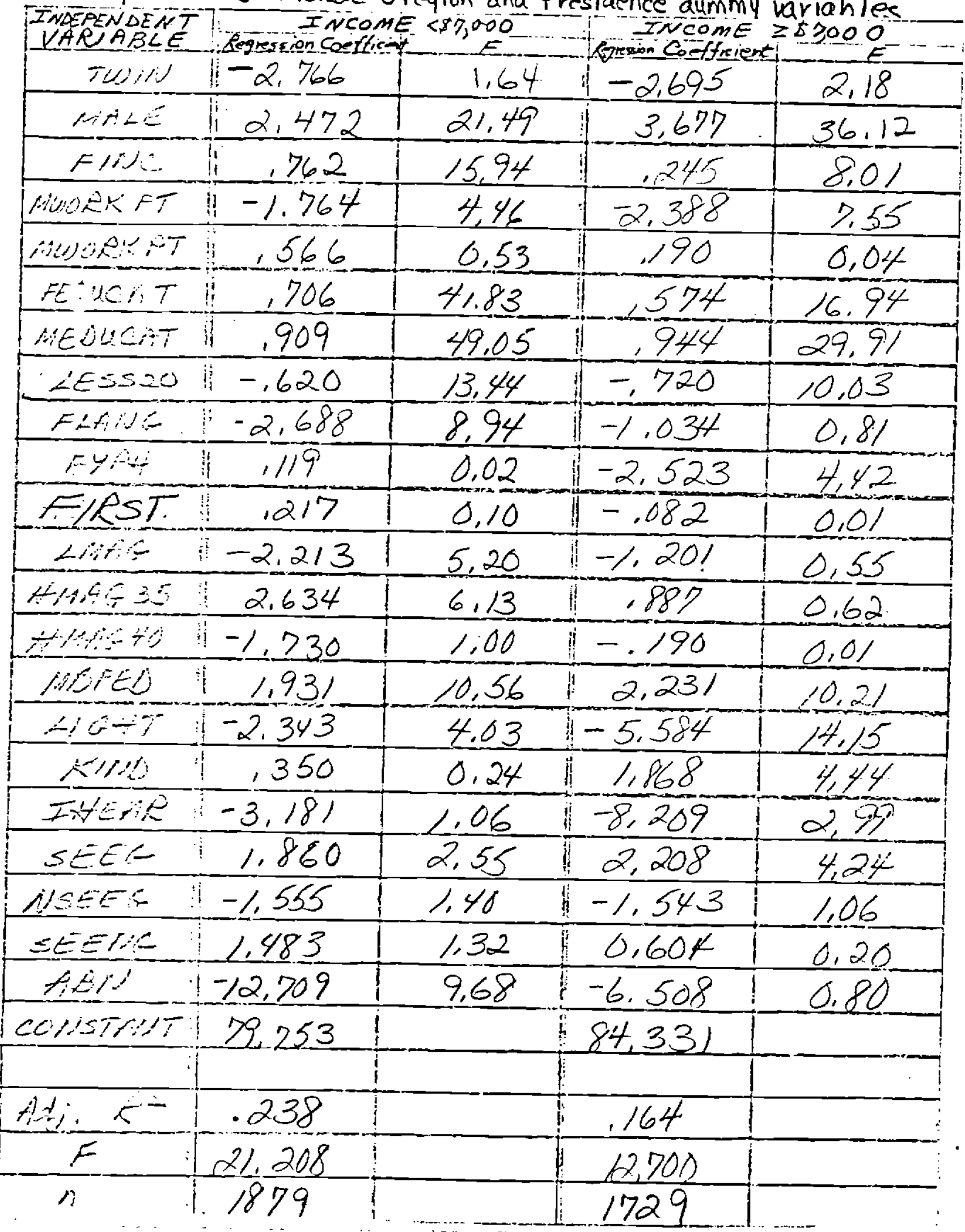


TABLE AQ

Ordinary Least Squares Regressions of RWRAT Regressions include 3 region and 4 residence dummy variables

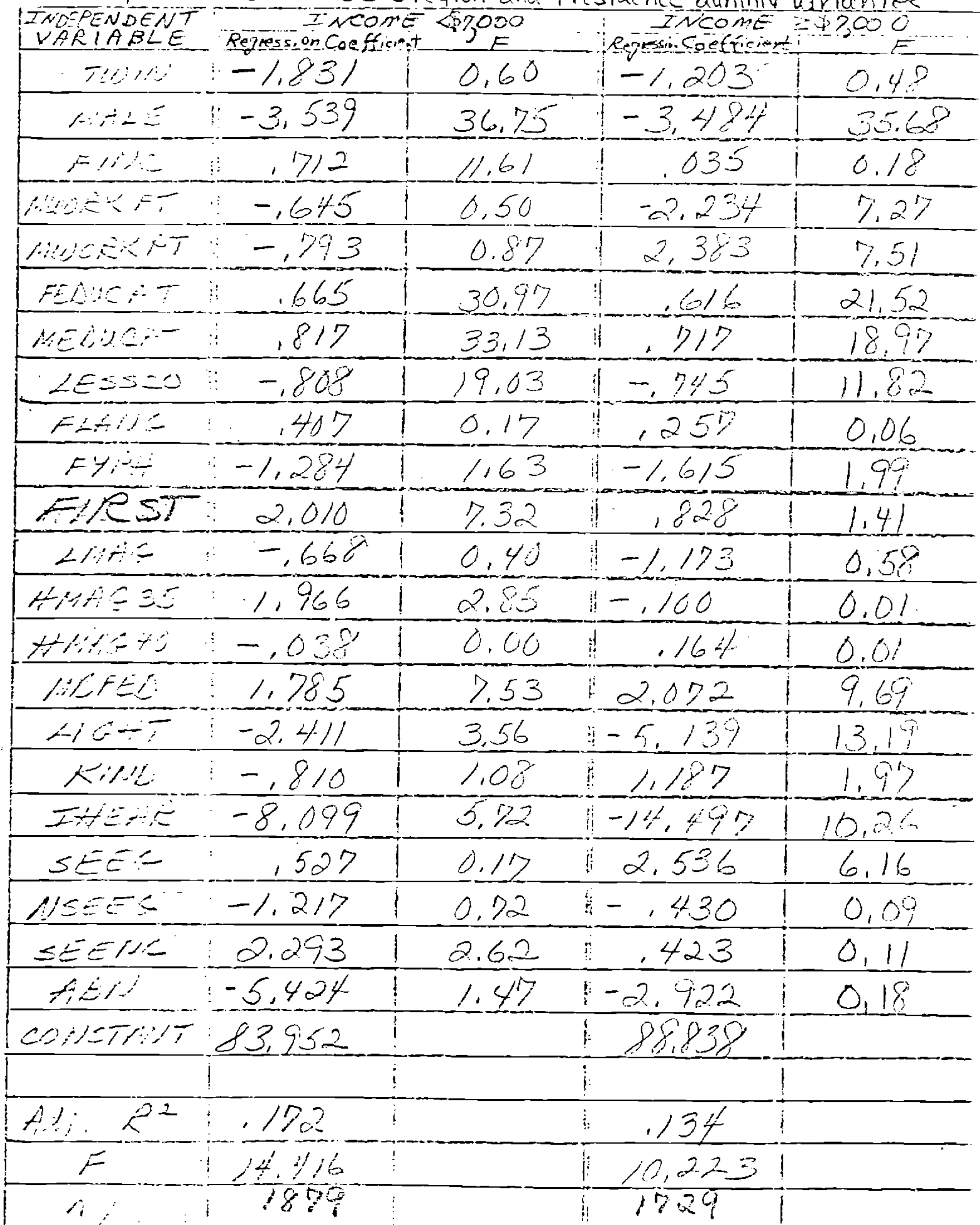


TABLE AB

Ordinary least Squares Regressions of AWRAT

Regressions include 3 region and 4 residence dummy variables

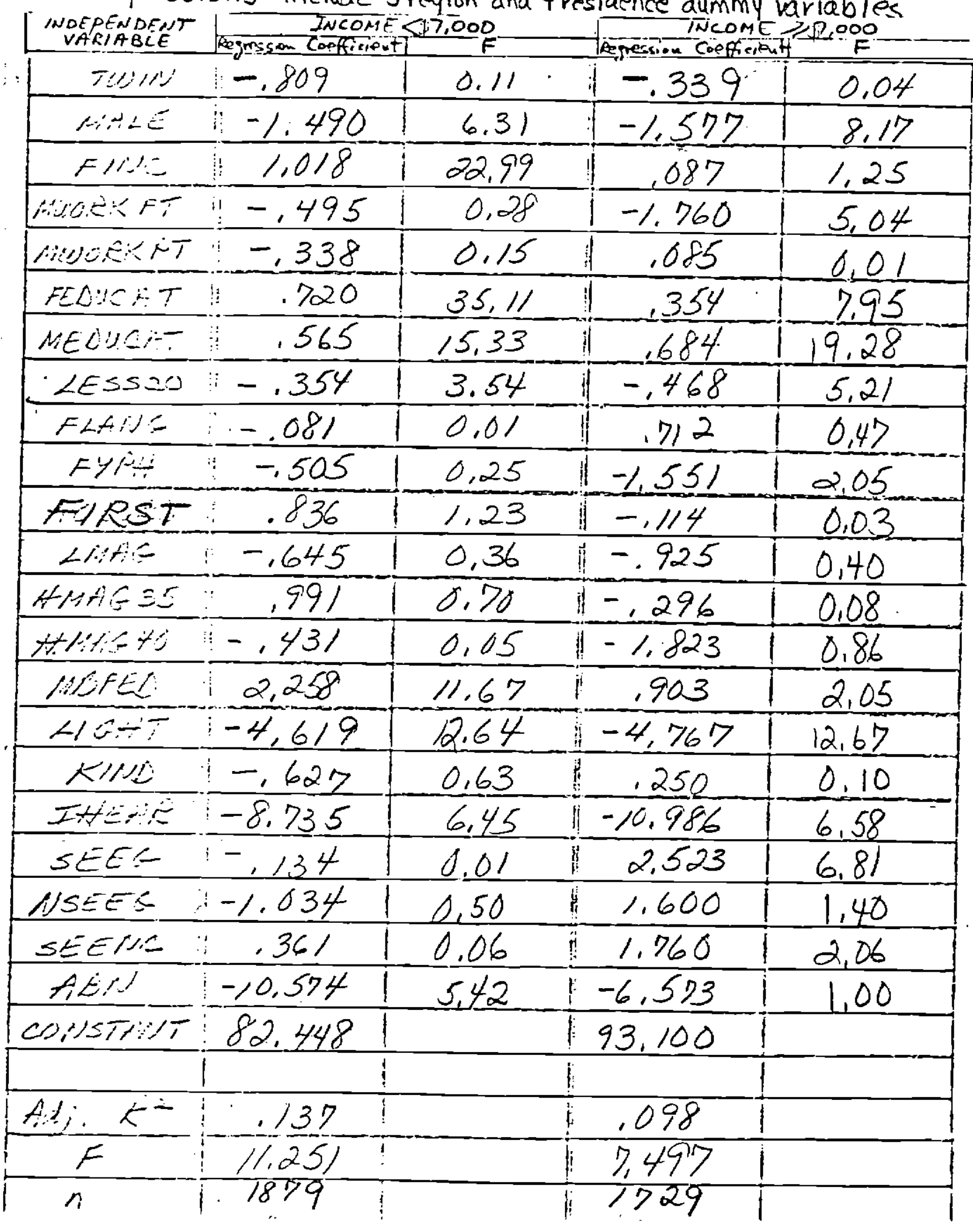


TABLE AH

Ordinary Least Squares Regressions of I HEIGHT Regressions include 3 region and 4 residence dummy variables

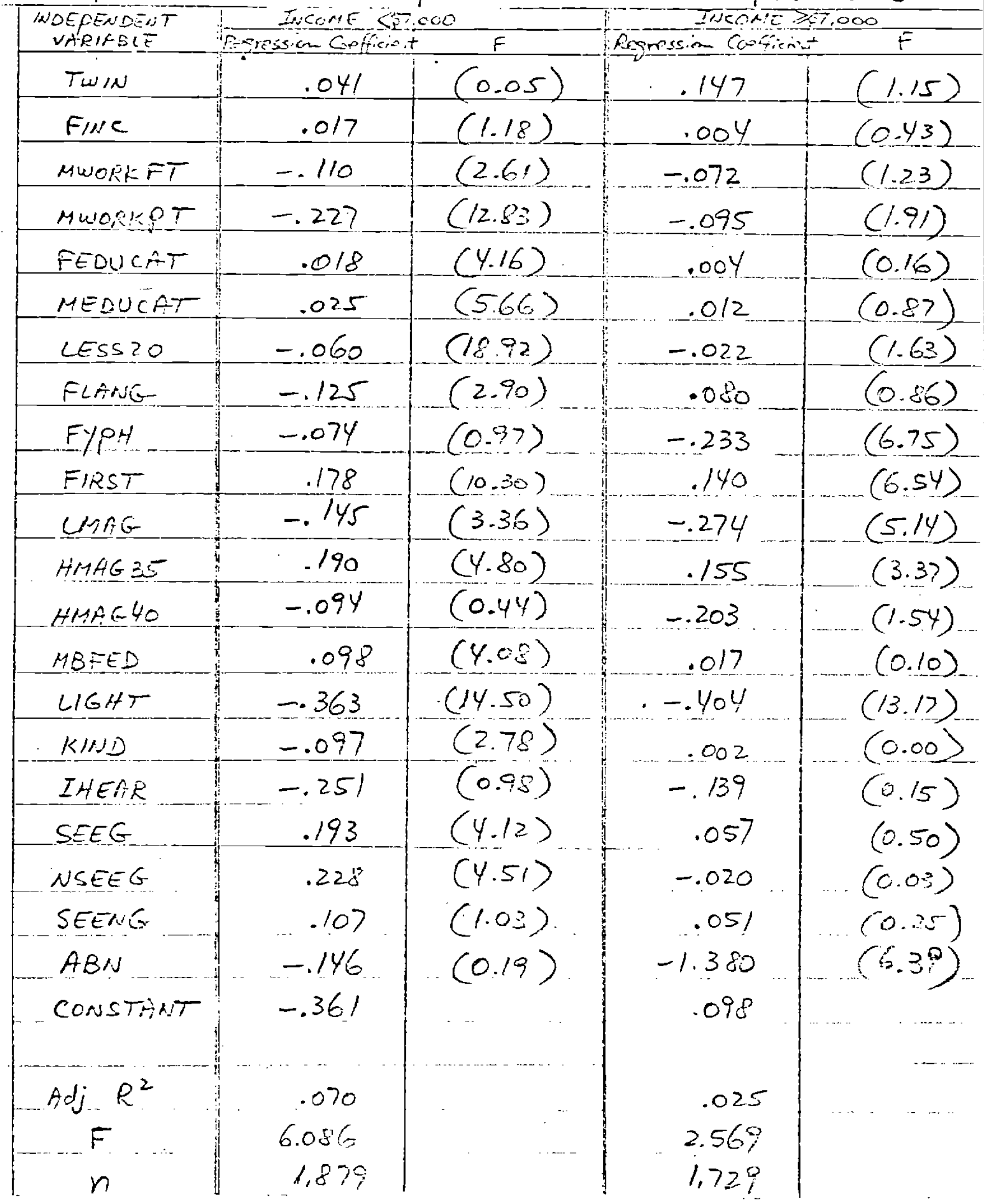


TABLE 5

Ordinary Least Squares. Regressions of IPERI

Regressions include 3 region and 4 residence dummy variables

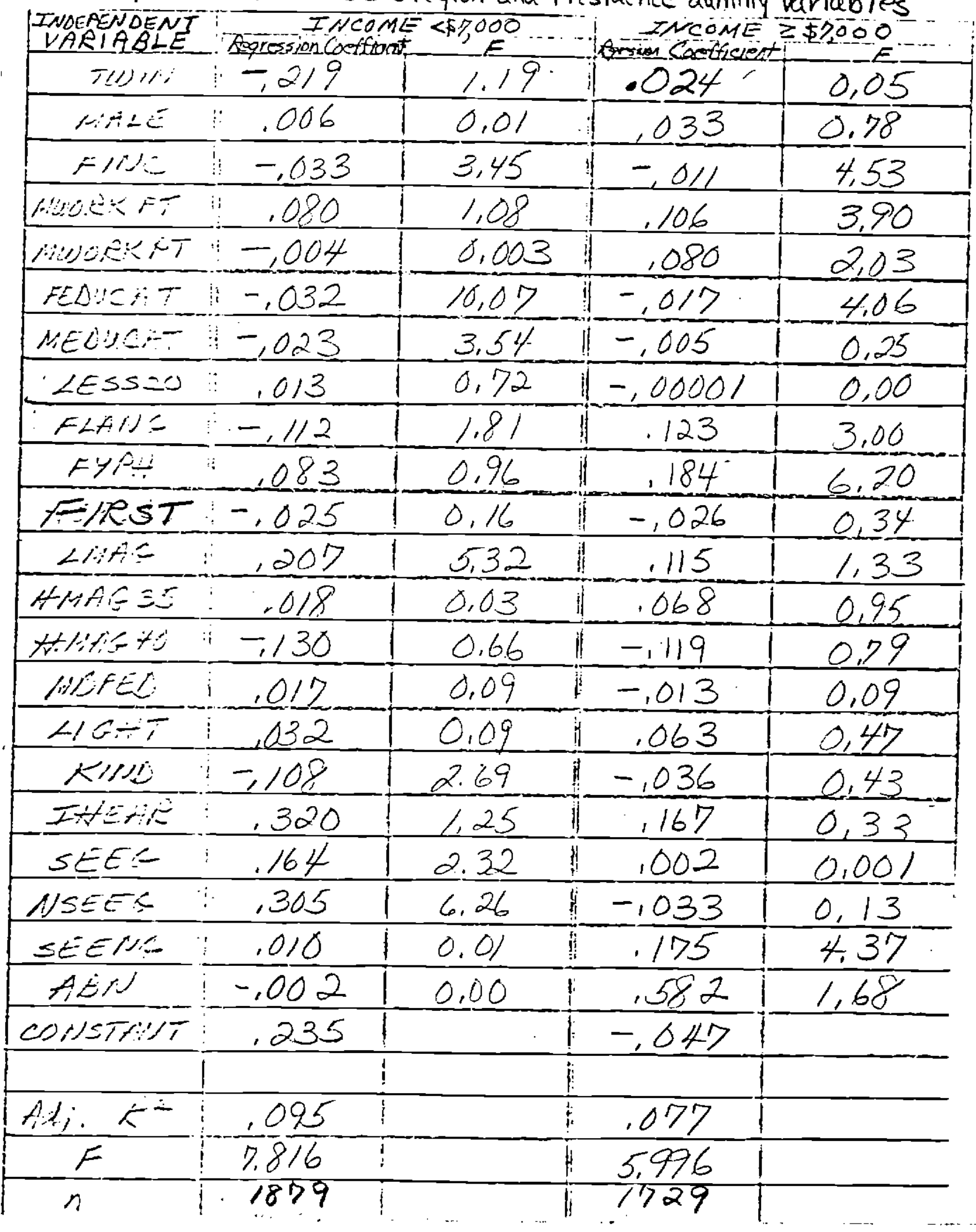


TABLE A 6

Ordinary Least squares Regressions of IDECAY Regressions include 3 region and 4 residence dummy variables

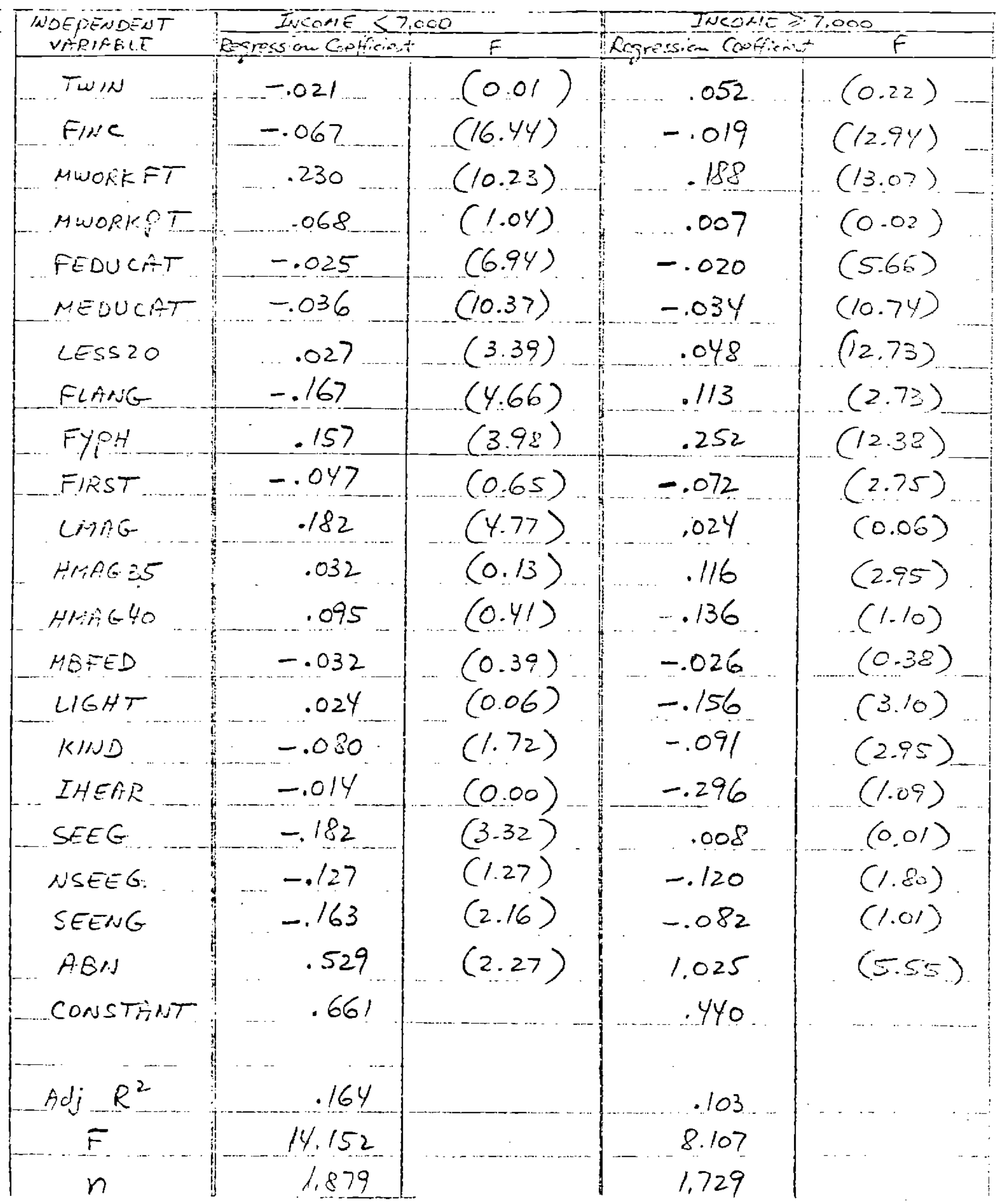


TABLE AT

Ordinary Least Squares Regressions of PFHEALTH Regressions include 3 region and 4 residence dummy variables.

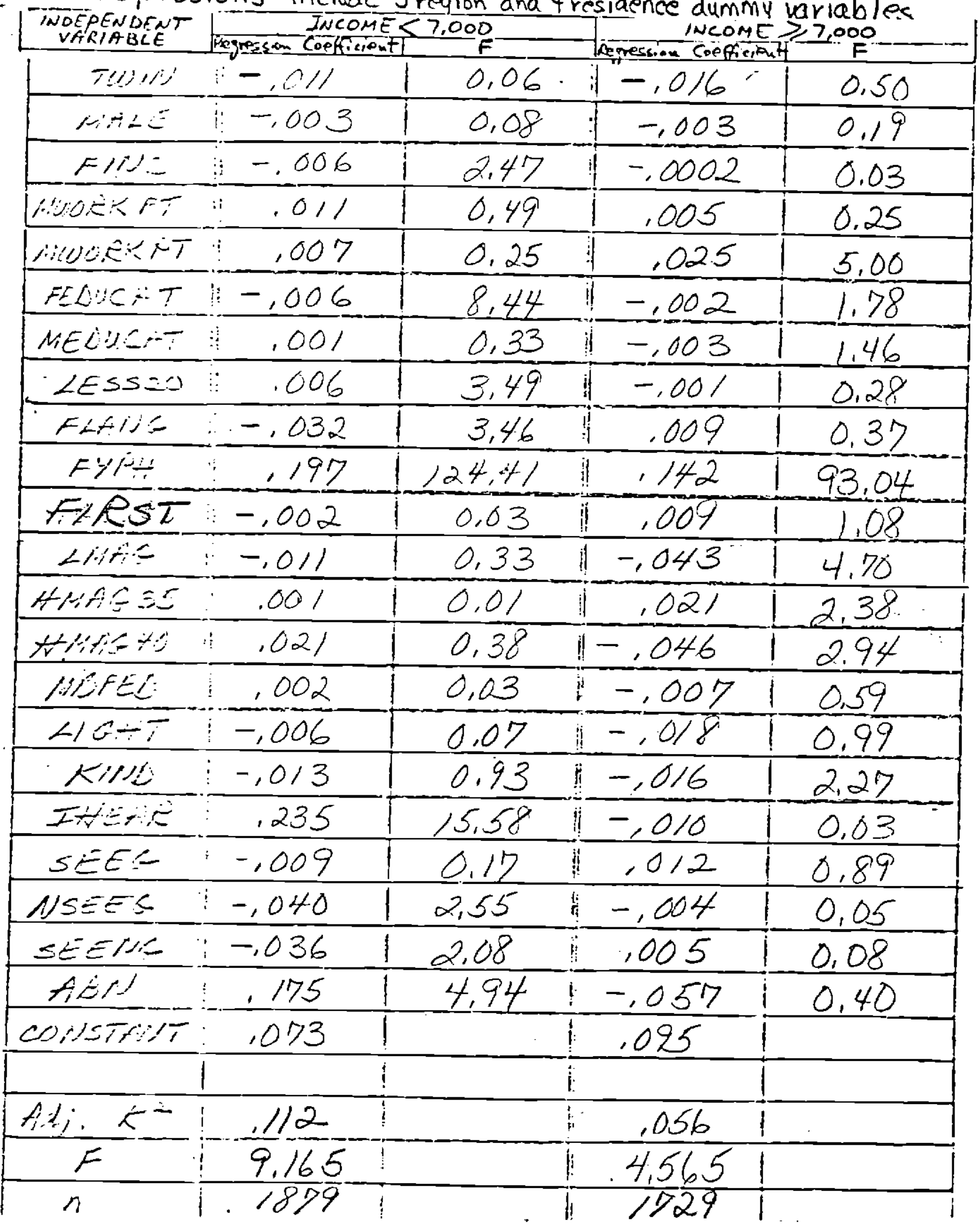


TABLE A 8

Ordinary Least Squares Regressions of WISC Regressions include 3 region arid 4 residence dummy variables

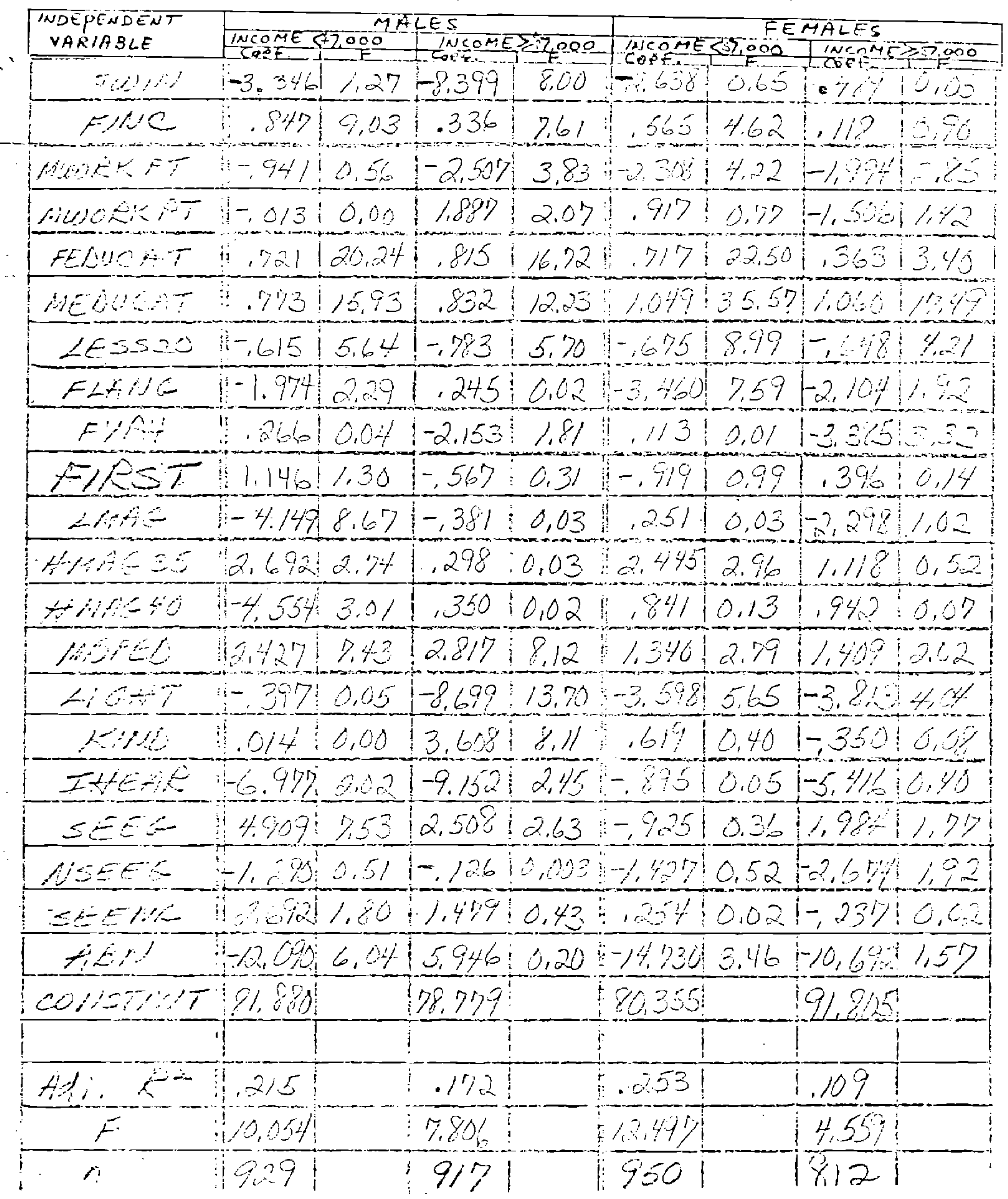


TABLE Aq

Ordinary Least Squares Regressions of RWRAT Regressions include 3 region and 4 residence dummy variables

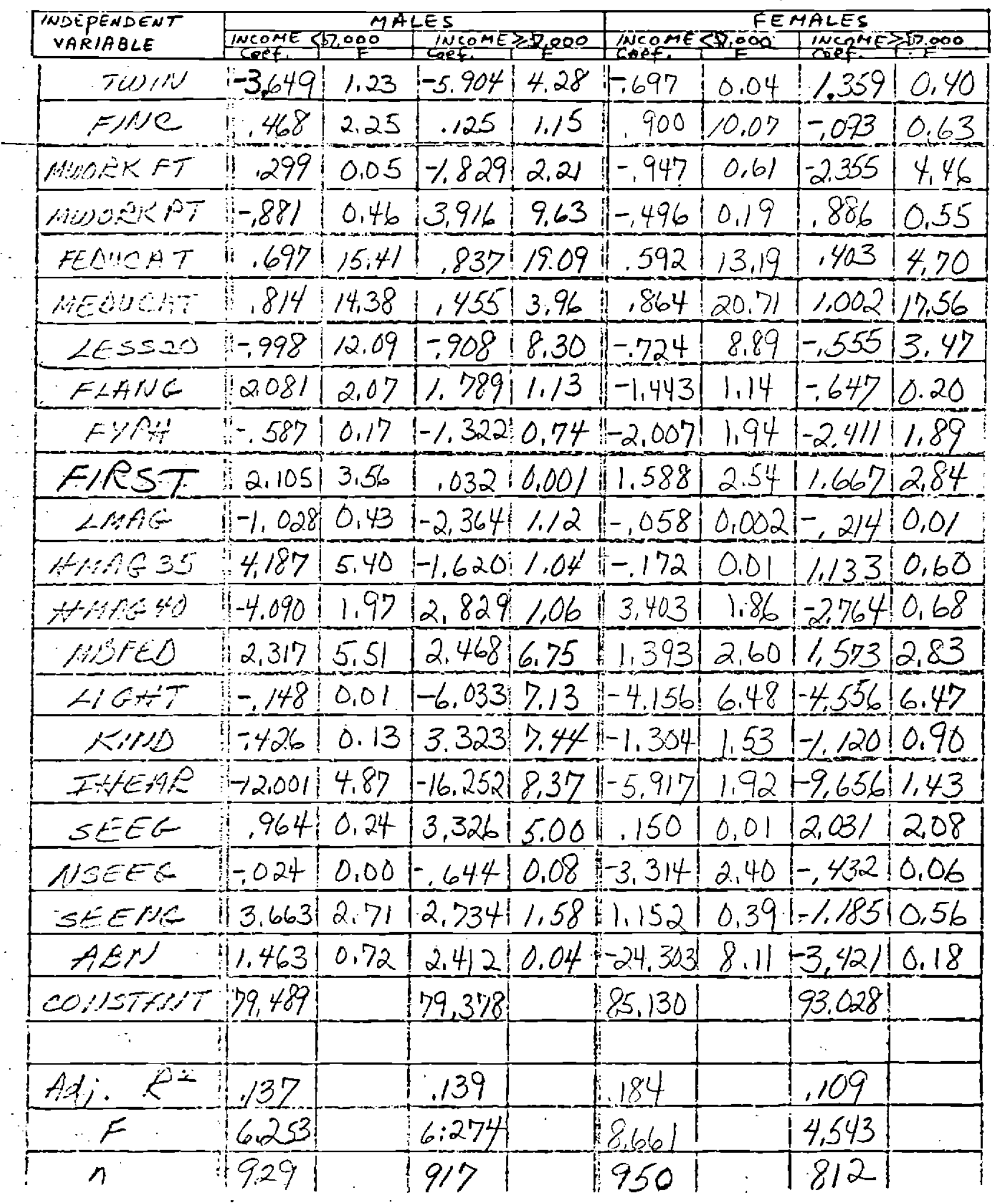


TABLE A lO

Ordinary Least Squares Regressions of AWRAT Regressions include 3 region and 4 residence dummy variables

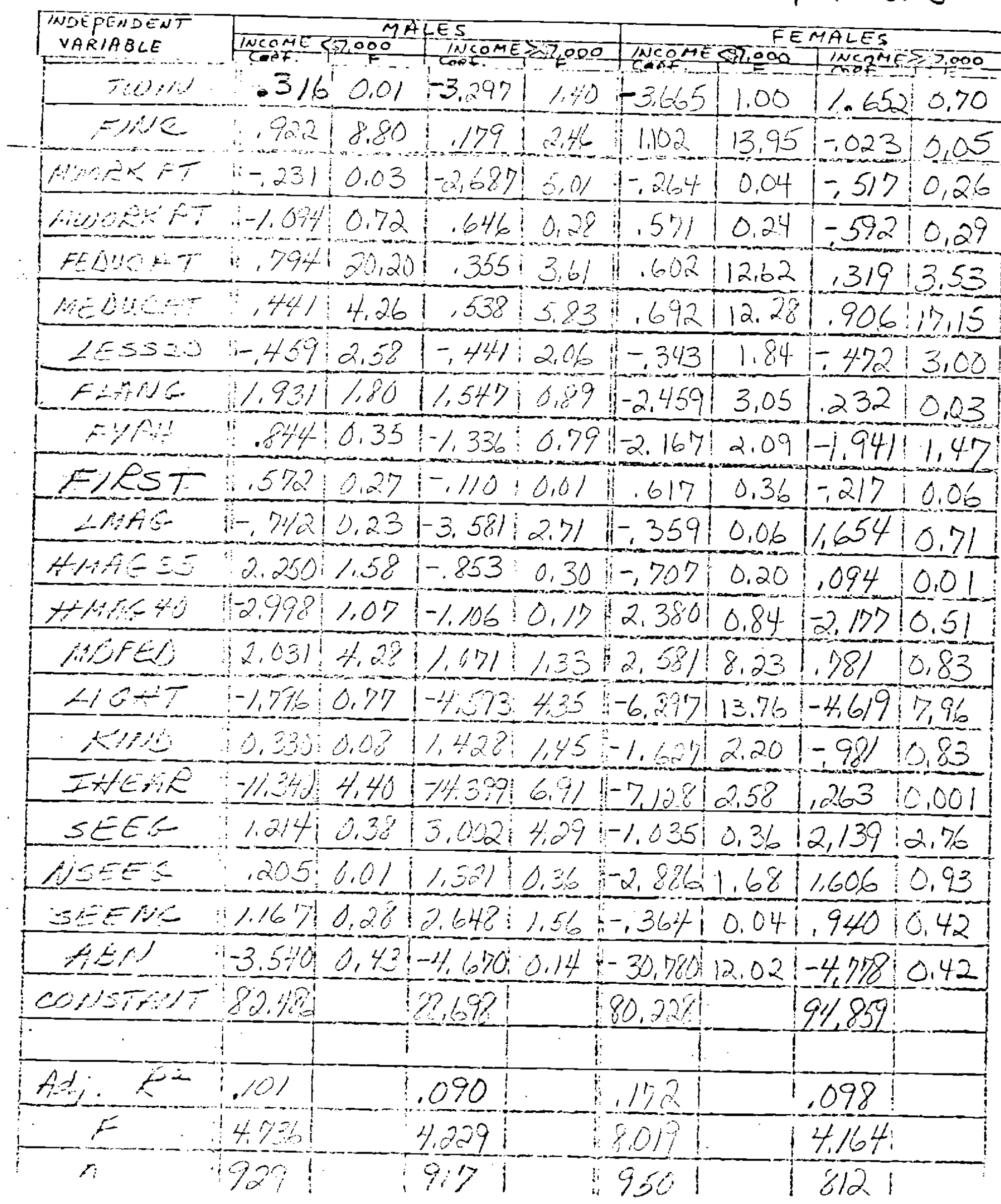


TABLE AlI

Ordinary Least Squares Regressions of IHEIGHT Regressions include 3 region and 4 residence dummy variables

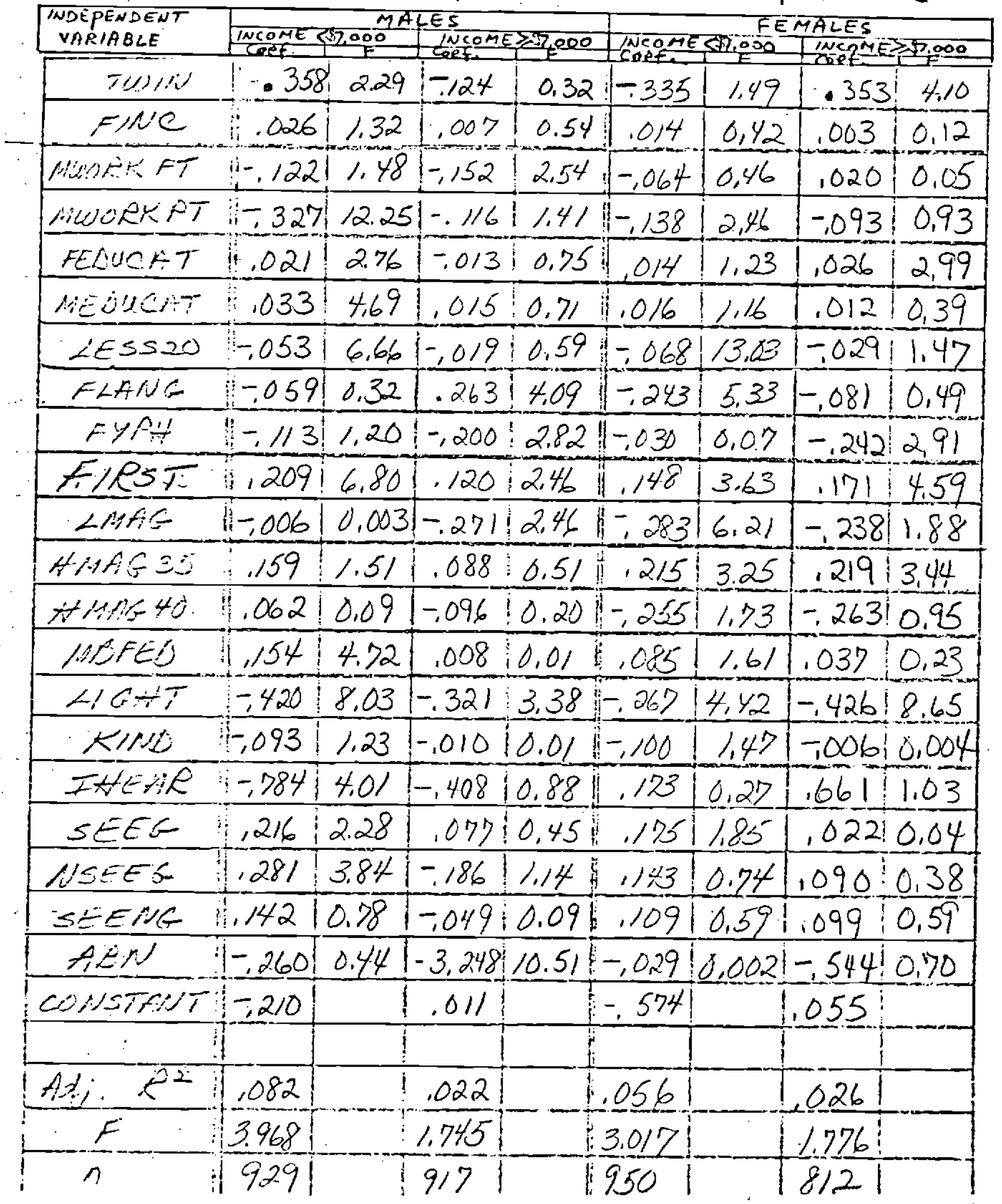


TABLE AIR

Ordinary Least Squares Regressions of IPERI

Regressions include 3 region and 4 residence dummy variables

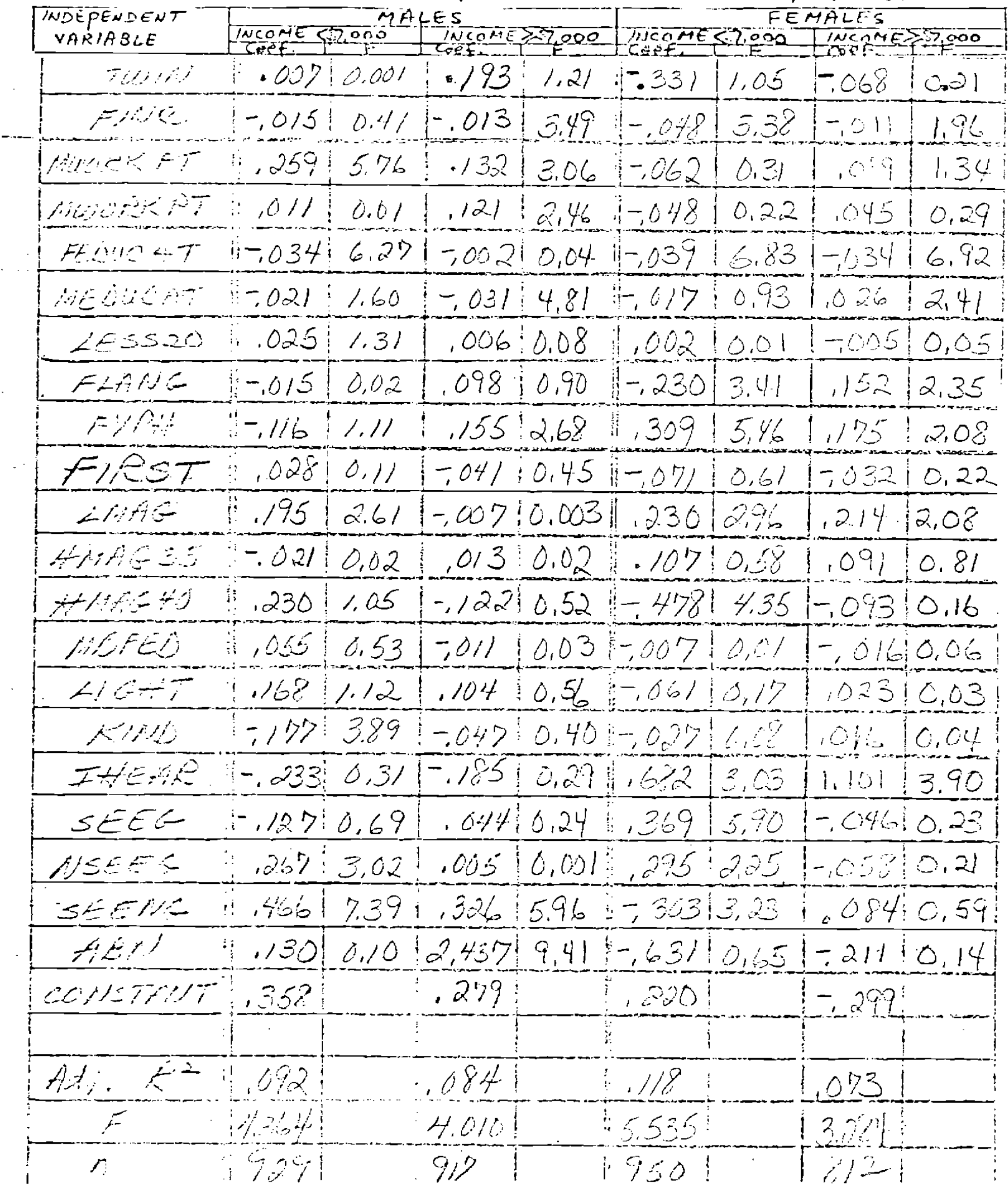


TABLE AI

Ordinary Least Squares Regressions of IDECAY

Regressions include 3 region and 4 residence dummy variables

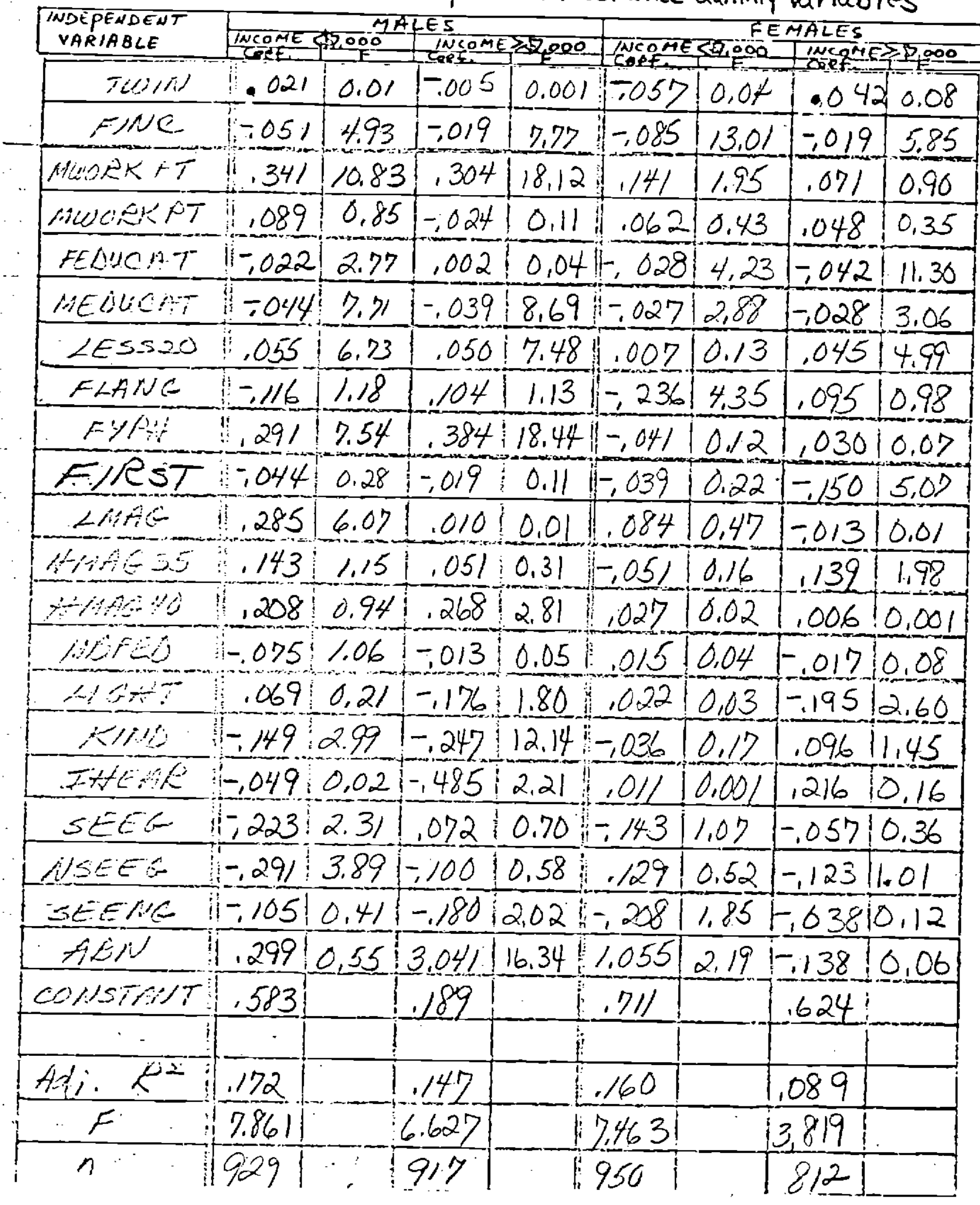


TABLE AI

Ordinary Least Squares Regressions of PFHEALTH

Regressions include 3 region and 4 residence dummy variables

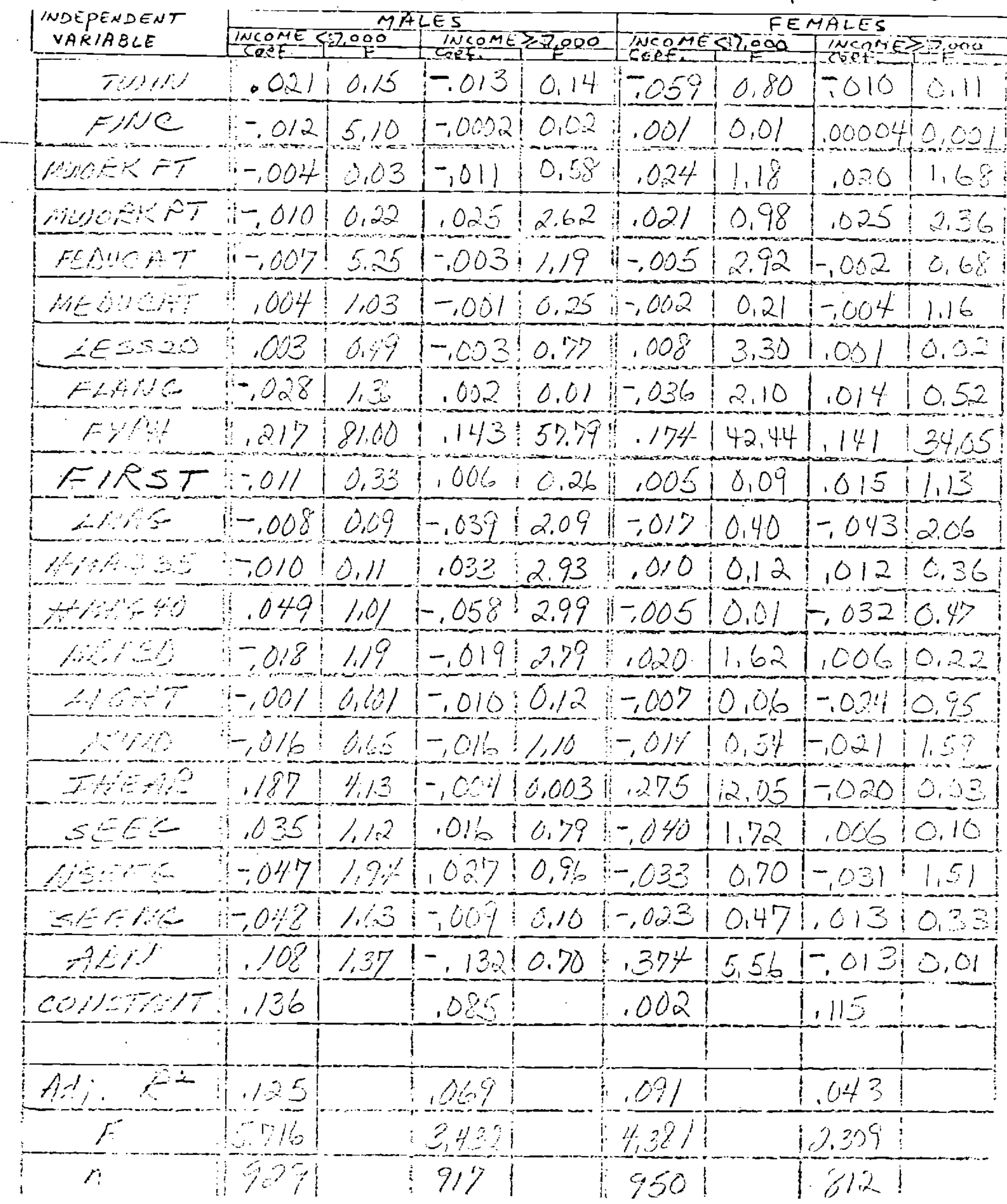


Ashenfelter, Orley, and Mooney, Joseph D. "Graduate Education, Ability and Earnings." The Review of Economics and Statistics, 50, No. 1 (February 1968).

Averch, Harvey A., et at. How Effective is Schooling? A Critical Review and Synthesis of Research Fincings. Santa Monica: The Rand Corporation, 1972.

Becker, Gary S. Human Capital and the Personal Distribution of Income: An Analytical Approach. W.S. Woytinsky Lecture No. 1. Ann Arbor: University of Michigan, 1967.

Becker, Gary S. "A Theory of Social Interactions." Journal of Political Economy, 82, No. 6 (November/December 1974).

Becker, Gary S., and Lewis, H. Gregg. "On the Interaction between the Quantity and Quality of Children." In New Economic Approaches to Fertility, edited by T.W. Schultz. Proceedings of a conference sponsored by the National Bureau of Economic Research and the Population Council. Journal of Political Economy, 81, No. 2. Part II (March/April 1973).

Becker, Gary S., and Tomes, Nigel. "Child Endowments and the Quantity and quality of Children." Journal of Political Economy, 84, No. 4, Part II (August 1976).

Ben-Porath, Yoram, and welch, Finis. "Do Sex Preferences Really Matter?" The Quarterly Journal of Economics, 90, No. 2 (May 1976).

Berg, Robert I. Health Status Indexes. Proceedings of a conference conducted by Health Services Research, Tuscon, Arizona, October 1972. Chicago: Hospital Research and Educational Trust. 1973.

Birch, Herbert G., and Gussow, Joan Dye. Disadvantaged Children: Health, Nutrition, and School Failure. New York: Harcourt, Brace and World, Inc., 1970.

Blinder, Alan S. "A Model of Inherited Wealth." The Quarterly Journal of Economics, 87. No. 4 (November 1973).

Bloom, Benjamin s. Stability and Change in Human Characteristics. New York: John Wiley and Sons, Inc., 1964.

Broman, Sarah H.: Nichols, Paul L.; and Kennedy, Wallace A. Preschool IQ: Prenatal and Early Developmental Correlates. Hillsdale, New Jersey: Lawrence Erlbaum Associates, Publishers, 1975. 
Carroll, John B. "Fitting a lodel of School Learning to Aptitude and Achievement Data over Grade Levels." Research Bulletin No. RB-73-51, Princeton, New Jersey: Educational Testing Service, 1973.

Edwards, Linda Nasif, and Grossman, Michael. "An Economic Analysis of Child Health and Intellectual Development." Presented at a Health Economics Research Organization session at the annual meetings of the Allied Social Science Associations, Atlantic City, New Jersey, September 1976.

Fisher, Irving. The Theory of Interest. New York: Augustus M. Kelley, 1961. Original edition, 1930 .

Friedman, Bernard, and Leibowitz, Arleen. "The Bequest Motive in Human Capital and the Health Care of Children." Unpublished paper, 1975.

Goldfield, S.M., and Quandt, R.E. "The Estimation of Structural Shifts by Switching Regressions." Annals of Economic and Social Measurement, 2, No. 4 (October 1973).

Gronau, Reuben. "Wage Comparisons - A Selectivity Bias." Journal of Political Economy, 82, No. 6 (November/December 1974).

Grossman, Michael. "The Correlation Between Health and Schooling." In Household Production and Consumption, edited by Nestor E. Terleckyj. New York: Columbia University Press for the National Bureau of Economic Research, 1975.

Haggerty, Robert J.; Roghmann, Klaus J.; and Pless, Ivan B. Child Health and the Community. New York: John Wiley and Sons, 1975.

Heckman, James J. "Effects of Child-Care Programs on Women's Work Effort." In T.w. Schultz, ed., Marriage, Family Human Capital, and Fertility. Proceedings of a conference sponsored by the National Bureau of Economic Research and the Population Council. Journal of Political Economy, 82, No. 2, Part II (March/April 1974).

Hu, Teh-Wei. "Effectiveness of Child Health and Welfare Programs: A Simultaneous Equations Approach." Socio-Economic Planning Sciences, 7 (1973).

Inman, Robert P. "The Family Provision of Childrens Health: An Economic Analysis." In The Role of Health Insurance in the Health Services Sector, edited by Richard Rosett. New York: Columbia University Press for the National Bureau of Economic Research, 1976.

Ishikawa, Tsuneo. "Family Structures and Family Values in the Theory of Income Distribution." Journal of Political Economy, 83, No. 5 (October 1975). 
Kamin, Leon J. The Science and Politics of IO. New York: John Wiley and Sons, 1974 .

Kaplan, Robert S.; Lave, Lester B.; and Leinhardt, Samuel. "The Efficacy of a Comprehensive Health Care Project: An Empirical Analysis." American Journal of Public Health, 62, No. 7 (July 1972).

Kenny, Lawrence $w$. "The Demand for Child quality and for Its Inputs, the Production of Child Quality and Related Topics." Ph.D. dissertation, University of Chicago, 1977.

Kessner, David M. Assessment of Medical Care for Children. Contrasts in Health Status, Vol. 3. Washington, D.C.: Institute of Medicine. 1974.

Lansing. John B.. and Sonquist, John. "A Cohort Analysis of Changes in the Distribution of Wealth." In Six Papers on the Size Distribution of Wealth and Income, edited by Lee Soltow. New York: Columbia University Press for the National Bureau of Economic Research, 1969.

Mechanic, David. "The Influence of Mothers on Their Children's Health, Attitudes and Behavior." Pediatrics, 33 (March 1964).

Mindlin, Rowland L.. and Lobach, Katherin S., "Consistency and Change in Choice of Medical Care for Preschool Children." Pediatrics. 48 (September 1971).

National Center for Health statistics. Anthropometric and Clinical Findings. U.S. Department of Health, Education, and Welfare, Public Health Service Publication No. (HRA) 75-1229. April 1975.

National Center for Health Statistics. Binocular Visual Acuity of Children: Demographic and Socioeconomic Characteristics - United States. U.S. Department of Health, Education, and Welfare. Vital and Health Statistics - Series 11 - No. $112,1972 \mathrm{a}$.

National Center for Health Statistics. Evaluation of Psychological Measures Used in the Health Examination Survey of Children Ages 6-11. U.S. Department of Health, Education, and Welfare. Public Health Service Publication No. 1000 - Series 2 - No. 15. 1966.

National Center for Health Statistics. Hearing Levels of Children by Age and Sex: United states. U.S. Department of Health, Education. and Welfare. Public Health Service Publication No. 1000 Series 11 - No. 102, 1970a. 
National Center for Health Statistics. Height and Weight of Children: United States. U.S. Department of Health, Education, and Helfare, Public Health Service Publication No. 1000 Serles 11 - No. 119,1970 b.

National Center for Health Statistics. Periodontal Disease and Oral Hygiene Among Children: United States. U.S. Department of Health, Education, and Helfare, Vital and Health Statistics Series 11 - No. 117, 1972b.

National Center for Health Statistics. Plan, Operation, and Response Results of a Program of Children's Examinations. U.S. Department of Health, Education, and Nelfare, Public Health Service Publication No. 1000 - Series 1 - No. 5, 1967a.

National Center for Health Statistics. A Study of the Achievement Test Used in the Health Examination Survey of Persons Aged 6-17 Years. U.S. Department of Health, Education, and Welfare, Public Health Service Publication No. 1000 - Series 2 - No. 24, $1967 b$.

Owen, George M. "The Assessment and Recording of Measurements of Growth of Children: Report of a Small Conference." Pediatrics, 51 (March 1973).

Russell, A.L. "A System of Classification and Scoring for Prevalence Surveys of Periodontal Disease." Jounal of Dental Research, 35 (June 1956).

Seoane, Nicole, and Latham, Michael c. "National Anthropometry in the Identification of Malnutrition in Childhood." Joumal of Tropical Pediatric and Environmental Child Health (September 1971).

Schack, Elisabeth, and Starfield, Barbara. "Acute Disability in Childhood: Examination of Agreement between Various Measures." Medical Care, 11. No. 4 (July - August 1973).

Starfield, Barbara. "Health Needs of Children." Prepared for the Robert Wood Johnson Foundation, 1975.

Sullivan, Daniel F. "Conceptual Problems in Developing an Index of Health." PHS Pub. No. 1000. Vital and Health statistics Series 2, No. 17. Rockville, Maryland: National Center for Health Statistics, 1966.

Talbot, Nathan B.: Kagan, Jerome; and Eisenberg, Leon, editors. Behavioral Science in Pedlatric Medicine. Philadelphia: W.B. Saunders Company, 1971. 
Tomes, Nigel. "Intergenerational Transfers of Human and Non-Human Capital in a Model of Quality-Quantity Interaction." Ph.D. dissertation, University of Chicago, 1977.

Wallace, Helen M. Health Services for Mothers and Children. Philadelphia: W.B. Saunders Company, 1962.

Ware, Jr., John E. "The Conceptualization and Measurement of Health for Policy Relevant Research in Medical Care Delivery." Presented at the annual meeting of the American Association for the Advancement of Science, Boston, Massachusetts, February 1976.

Willis, Robert. "A New Approach to the Economic Theory of Fertility Behavior." In New Economic Approaches to Fertility, edited by T.W. Schultz. Proceedings of a conference sponsored by the National Bureau of Economic Research and the Population Council. Journal of Political Economy, 81, No. 2, Part II (March/Aoril 1973). 